\title{
Relationship between chemical composition and oxidative potential of secondary organic aerosol from polycyclic aromatic hydrocarbons
}

\author{
Shunyao Wang ${ }^{1}$, Jianhuai Ye ${ }^{1}$, Ronald Soong ${ }^{2}$, Bing Wu ${ }^{2}$, Legeng Yu ${ }^{1}$, André J. Simpson ${ }^{2}$, and Arthur W. H. Chan ${ }^{1}$ \\ ${ }^{1}$ Department of Chemical Engineering \& Applied Chemistry, University of Toronto, Toronto, Ontario, Canada \\ ${ }^{2}$ Environmental NMR Centre, Department of Physical and Environmental Sciences, University of Toronto Scarborough, \\ Toronto, Ontario, Canada
}

Correspondence: Arthur W. H. Chan (arthurwh.chan@utoronto.ca)

Received: 29 October 2017 - Discussion started: 10 November 2017

Revised: 16 February 2018 - Accepted: 19 February 2018 - Published: 22 March 2018

\begin{abstract}
Owing to the complex nature and dynamic behaviors of secondary organic aerosol (SOA), its ability to cause oxidative stress (known as oxidative potential, or OP) and adverse health outcomes remains poorly understood. In this work, we probed the linkages between the chemical composition of SOA and its OP, and investigated impacts from various SOA evolution pathways, including atmospheric oligomerization, heterogeneous oxidation, and mixing with metal. SOA formed from photooxidation of the two most common polycyclic aromatic hydrocarbons (naphthalene and phenanthrene) were studied as model systems. OP was evaluated using the dithiothreitol (DTT) assay. The oligomerrich fraction separated by liquid chromatography dominates DTT activity in both SOA systems $(52 \pm 10 \%$ for naphthalene SOA (NSOA), and $56 \pm 5 \%$ for phenanthrene SOA (PSOA)). Heterogeneous ozonolysis of NSOA was found to enhance its OP, which is consistent with the trend observed in selected individual oxidation products. DTT activities from redox-active organic compounds and metals were found to be not additive. When mixing with highly redox-active metal $(\mathrm{Cu})$, OP of the mixture decreased significantly for 1,2-naphthoquinone $(42 \pm 7 \%), 2,3$-dihydroxynaphthalene $(35 \pm 1 \%)$, NSOA $(50 \pm 6 \%)$, and PSOA $(43 \pm 4 \%)$. Evidence from proton nuclear magnetic resonance $\left({ }^{1} \mathrm{H}\right.$ NMR) spectroscopy illustrates that such OP reduction upon mixing can be ascribed to metal-organic binding interactions. Our results highlight the role of aerosol chemical composition under atmospheric aging processes in determining the $\mathrm{OP}$ of SOA, which is needed for more accurate and explicit prediction of the toxicological impacts from particulate matter.
\end{abstract}

\section{Introduction}

Exposure to particulate matter (PM) has been associated with various adverse health outcomes, such as increased risks of myocardial infarction, ischemic heart disease, lung cancer, exacerbation of asthma, and chronic obstructive pulmonary disease (de Kok et al., 2006; Li et al., 2003a, b; Nel, 2005; Risom et al., 2005; Thurston et al., 2016). As a result, ambient $\mathrm{PM}_{2.5}$ exposure ranks among the top five global mortality risk factors (Cohen et al., 2017). Meanwhile, decreased ambient PM levels have been associated with longer life expectancies (Pope et al., 2009). To establish causal links between aerosol exposure and health outcomes, cytotoxic and carcinogenic potential has been investigated by epidemiological studies in the past decades (Brunekreef and Holgate, 2002; Beelen et al., 2014; Lelieveld et al., 2015; Pope et al., 2002), but the underlying mechanistic pathways by which PM causes adverse health outcomes still remain poorly understood.

Oxidative stress has been proposed as one of the main mechanisms for PM toxicity in recent years, and is caused by oxidative potential (OP; Li et al., 2003b). OP is exhibited as the capacity of inhaled PM to induce oxidative stress, the redox imbalance generated through consumption of antioxidants and production of reactive oxygen species (ROS) (Antiñolo et al., 2015; Shen et al., 2011; Shiraiwa et al., 2012). ROS include a variety of oxidants such as superoxide $\left(\mathrm{O}_{2}^{--}\right)$, hydroxyl radical $(\cdot \mathrm{OH})$, and hydrogen peroxide $(\mathrm{HOOH})$, which could either be introduced into human body directly from inhaled PM or generated by targeted cells (Nel et al., 1998; Pöschl and Shiraiwa, 2015; Rhee, 2006; Verma et al., 2015b). The generation of ROS during multiphase in- 
teractions between air pollutants and the human respiratory tract is closely related to the chemical composition, since the combination of various pollutants may influence chemical reactivity as well as bioavailability of PM while having synergistic or nonlinear influences on its OP (Antiñolo et al., 2015; Charrier et al., 2015; Fang et al., 2015; Shiraiwa et al., 2012; Xiong et al., 2017).

OP of both organic and inorganic PM components have been evaluated by both cellular and acellular assays. In vitro cellular assays were conducted by detecting biological endpoints of the exposure, including heme oxygenase-1 (HO-1) and other cytokines as well as macrophage-related biomarker expressions (Krapf et al., 2017; Li et al., 2003b). On the other hand, acellular assays use specific chemicals, such as dithiothreitol (DTT), ascorbate (AA), and glutathione (GSH), as surrogates of low molecular weight (MW) antioxidants (Fang et al., 2016; Godri et al., 2011; McWhinney et al., 2013). Among acellular assays, the DTT assay quantifies OP by measuring the DTT depletion rate over a fixed time interval, which mimics the physiological process of electron transfer from biological antioxidants to dissolved $\mathrm{O}_{2}$ (Cho et al., 2005). DTT assay is one of the most commonly used OP evaluation methods since DTT is a potent surrogate for the total thio-pools (glutathione and protein thiols), and this assay can be conducted under biologically relevant conditions $\left(37^{\circ} \mathrm{C}, \mathrm{pH}=7.4\right)$ with relatively simple procedures (Cleland, 1964; Hansen et al., 2009; McWhinney et al., 2011). OP levels measured by this assay have been found to correlate well with cellular ROS expression as well as several airway inflammation biomarkers, such as HO-1, tumor necrosis factor- $\alpha$ (TNF- $\alpha)$ and fractional exhaled nitric oxide ( $\left.\mathrm{FE}_{\mathrm{NO}}\right)$ (Delfino et al., 2013; Li et al., 2003b; Tuet et al., 2017a).

Secondary organic aerosol (SOA) from atmospheric oxidation of gaseous precursors comprises a major fraction of submicron particulate matter. To date, the DTT assay has been applied in a few studies to evaluate the OP of both laboratory and ambient SOA (McWhinney et al., 2013; Tuet et al., 2017b; Verma et al., 2015a). However, owing to the complex and dynamic property of SOA, there is limited understanding of the relationship between detailed SOA composition and its OP (Charrier and Anastasio, 2012; Pöschl and Shiraiwa, 2015; Tuet et al., 2017b). Tuet et al. (2017b) studied the DTT activity of chamber-generated SOA from both biogenic and anthropogenic volatile organic compounds under various conditions, showing that naphthalene SOA (NSOA) has the highest OP. Previous work (Antiñolo et al., 2015; Bolton et al., 2000; Charrier and Anastasio, 2012; Cho et al., 2005; Jiang et al., 2017; Tuet et al., 2017b) indicated that polycyclic aromatic hydrocarbons (PAHs) are unreactive towards DTT while their oxidation products, such as quinones, can be highly redox-active. Quinones can be directly emitted from traffic or formed from secondary oxidation (Cho et al., 2004; McWhinney et al., 2013), and are able to consume antioxidants in a catalytic cycle (Fig. 1; Bolton et al., 2000; Valavanidis et al., 2005). McWhin-

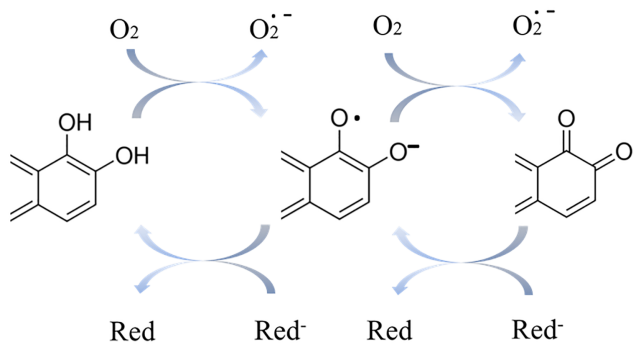

Figure 1. A simplified mechanism of redox cycling of quinone-like substances and formation of superoxide anion radicals. Red shows a general reductant. In the redox cycle, regenerated quinone serves as a chemical intermediate to transfer electrons from reductants to oxygen to form superoxide $\left(\mathrm{O}_{2}^{\bullet}\right)$.

ney et al. (2013) found three quinones (1,2-naphthoquinone, 1,4-naphthoquinone, and 5-hydroxy-1,4-naphthoquinone) in NSOA could only account $30 \pm 5 \%$ for the observed OP of NSOA, and the source of the remaining DTT activity remains unknown. Peroxides, which are the major contributors to the OP of isoprene SOA (Jiang et al., 2017; Lin et al., 2016; Surratt et al., 2010), may also be abundant in NSOA (Kautzman et al., 2010), but their contribution to the OP of NSOA has not been evaluated. In addition, the composition of SOA may evolve upon atmospheric aging. A previous study (Verma et al., 2009) found ambient samples collected in the afternoon had a larger fraction of water soluble organic carbon and higher OP, suggesting the photochemical aging effects. There may also be correlations between the average carbon oxidation state $(\overline{\mathrm{OS}} \mathrm{c})$ and $\mathrm{OP}$ of SOA at different stages of oxidation (Tuet et al., 2017a). Moreover, mixing between organics and metals was also found to change the OP of specific components in SOA (Xiong et al., 2017), but the mechanisms remain the tip of iceberg.

Here, we focused on understanding how the composition of PAH-derived SOA is related to its strong OP (Tuet et al., 2017b). We aim to address the following specific questions in this work: what are the compounds within SOA that are important for DTT activity? How does the OP change upon atmospheric aging processes, including oligomerization, heterogeneous oxidation, and mixing with transition metals (Gao et al., 2004; Rudich et al., 2007)? In this work, SOA from photooxidation of naphthalene and phenanthrene was studied as model systems, and compared to SOA from ozonolysis of $\alpha$-pinene and limonene. The relative OP contributions of peroxides and high MW oligomers were evaluated. Effects of aerosol aging on OP was evaluated by examining the OP of individual oxidation products known to be present in NSOA, and the OP of NSOA samples that were further oxidized in the condensed phase. Lastly, the impacts of SOA mixing with metal was explored by mixing SOA or redox-active SOA components with $\mathrm{Cu}$ (II), a transition metal which has been identified with the highest OP in am- 
bient particles (Charrier and Anastasio, 2012). Additivity of OP revealed by DTT assay was investigated, and the mechanisms of $\mathrm{Cu}$-organic interactions were examined in detail using proton nuclear magnetic resonance spectroscopy $\left({ }^{1} \mathrm{H}\right.$ NMR).

\section{Methods}

\subsection{Flow tube experiments}

SOA was produced in a custom-built $10 \mathrm{~L}$ quartz flow tube. Details about the flow tube conditions have been described in previous work (Ye et al., 2016, 2017). Prior to each experiment, the flow tube was flushed with purified compressed air at a flow rate of $20 \mathrm{~L} \mathrm{~min}^{-1}$ for over $24 \mathrm{~h}$.

To produce SOA from naphthalene or phenanthrene, solid PAH was placed in a heated container $\left(80^{\circ} \mathrm{C}\right)$, and the sublimed vapor was carried into the flow tube at a $0.2 \mathrm{~L} \mathrm{~min}^{-1}$ flow of purified compressed air. $\mathrm{O}_{3}$ and water vapor were also added into the flow tube. $\mathrm{O}_{3}$ was produced by passing $0.5 \mathrm{~L} \mathrm{~min}^{-1}$ oxygen (99.6\%, Linde, Mississauga, Canada) through an $\mathrm{UV} \mathrm{O}_{3}$ generator (no. 97006601, UVP, Cambridge, UK). Water vapor was produced by bubbling purified air through a custom-made humidifier with a flow rate of $1.3 \mathrm{~L} \mathrm{~min}^{-1}$. Residence time inside the flow tube was maintained around $5 \mathrm{~min}$. The flow tube was housed inside an aluminum enclosure, which was equipped with $254 \mathrm{~nm}$ UV lamps (UVP, Cambridge, UK). The photolysis of $\mathrm{O}_{3}$ produces $\mathrm{O}\left({ }^{1} \mathrm{D}\right)$, which reacts with water vapor to produce $\cdot \mathrm{OH}$ and initiate photooxidation of naphthalene/phenanthrene as well as SOA formation. During naphthalene/phenanthrene photooxidation, $\mathrm{O}_{3}$ concentration inside the flow tube was controlled around $1 \mathrm{ppm}$. In addition, blank experiments were conducted under the same conditions, without injecting any hydrocarbons.

Two types of SOA from monoterpene ozonolysis were also synthesized under similar conditions. Separately, $\alpha$-pinene (Sigma-Aldrich, 98\%) and limonene (Sigma-Aldrich, 97\%) were pre-dissolved in cyclohexane (Sigma-Aldrich, 99.5\%) with a volumetric ratio of $1: 500$ and $1: 1500$, respectively. At these ratios, the reaction rates between $\cdot \mathrm{OH}$ and cyclohexane are at least a hundred times higher than that of SOA precursors (Atkinson and Arey, 2003; Keywood et al., 2004). The experimental solution was injected continuously into purified air flow by a syringe $(1000 \mathrm{~mL}$, Hamilton) installed on a syringe pump (KDS Legato100) to achieve an initial concentration of $588 \pm 16$ or $298 \pm 24$ ppb of $\alpha$-pinene or limonene, respectively. $\mathrm{O}_{3}$ was produced by passing oxygen through the $\mathrm{O}_{3}$ generator at a flow rate of 0.2 or $0.3 \mathrm{~L} \mathrm{~min}^{-1}$ for $\alpha$-pinene or limonene, respectively, such that the $\mathrm{O}_{3}$ concentrations were at least 5 times higher than $\alpha$-pinene or limonene. Both experiments were conducted in the same flow tube without irradiation of UV lights.
Temperature and relative humidity were monitored by an Omega HX94C RH/T transmitter. The concentrations of SOA precursors at the inlet and outlet of the flow tube were measured by a gas chromatography-flame ionization detector (GC-FID, model 8610C, SRI Instruments Inc., LV, USA) equipped with a Tenax ${ }^{\circledR}$ TA trap. SOA size distribution and volume concentration at the flow tube reactor outlet were monitored using a custom-built scanning mobility particle sizer (SMPS), which was composed of a differential mobility analyzer column (DMA, model 3081, TSI, Shoreview, MN, USA) with flow controls and a condensation particle counter (CPC, model 3772, TSI, Shoreview, MN, USA). The SMPS data were inverted to particle size distributions using custom code written in Igor Pro (Wavemetrics, Portland, OR, USA). By assuming a particle density of $1.25 \mathrm{~g} \mathrm{~cm}^{-3}$ for monoterpene SOA (Kostenidou et al., 2007; Shilling et al., 2009) and $1.55 \mathrm{~g} \mathrm{~cm}^{-3}$ for PAH SOA (Chan et al., 2009; McWhinney et al., 2011), particle volume concentrations were converted into mass concentrations and integrated as a function of sample collection time and flow rates to obtain the total mass of collected SOA.

\subsection{SOA sampling and extraction}

All SOA samples were collected on $47 \mathrm{~mm}$ prebaked $\left(500^{\circ} \mathrm{C}, 24 \mathrm{~h}\right)$ quartz fiber filters (Pall, Ann Arbor, MI, USA) in a stainless-steel filter holder after reaching a steady state yield, and then wrapped in prebaked aluminum foil before being stored in sterile petri dishes sealed with Parafilm $\mathrm{M}^{\circledR}$ at $-20^{\circ} \mathrm{C}$. Within 3 days of collection, the filters were extracted in methanol (HPLC grade, $99.9 \%$, Sigma-Aldrich, St. Louis, MO, USA), by ultra-sonication at room temperature for more than $3 \mathrm{~min}$. After sonication, insoluble materials were filtered by a PTFE (polytetrafluoroethylene) syringe filters $\left(\right.$ Fisherbrand ${ }^{\mathrm{TM}}$ ) with pore size of $0.22 \mu \mathrm{m}$. Chemical analysis and DTT activities of the filter extracts were conducted within hours of extraction. As negative control, filter samples were also collected during blank experiments and extracted in the same manner.

\subsection{DTT assay}

OP of SOA and selected quinone/peroxide standards were quantified by the depletion rate of DTT, an antioxidant surrogate that can be consumed by oxidative components in PM (Kumagai et al., 2002). The protocols used in this work are adapted from those of McWhinney et al. (2011, 2013). The SOA extracts were first evaporated to complete dryness in a $5.0 \mathrm{~L} \mathrm{~min}^{-1}$ of $\mathrm{N}_{2}$ using a blow-off system (N-EVAP, Organomation, USA). Phosphate buffer (0.1 M, pH 7.4) was then added to dissolve the SOA to achieve a concentration of $0.2 \mathrm{mM}$. For quinones, copper (II) sulfate, and peroxides, each pure compound was weighed and dissolved in $0.1 \mathrm{M}$ phosphate buffer. The concentration of quinones and copper (II) sulfate solutions was $1 \mu \mathrm{M}$, and the concentration 
of each peroxide solution was $120 \mu \mathrm{M}$. The specific solution was then added into multiple wells in a 96-well UV plate (Greiner Bio-One, Kremsmünster, AT) with $160 \mu \mathrm{L}$ per well, and immediately covered with adhesive plate sealer (EdgeBio, Gaithersburg, USA). The plate was then placed in a UVVis spectrophotometer (Spectramax 190, Molecular Devices Corporation, Sunnyvale, CA) for incubation. The incubation temperature was maintained at $37^{\circ} \mathrm{C}$ inside the spectrophotometer to mimic human physiological conditions. Then, $0.02 \mathrm{~mL}$ DTT $(0.2 \mathrm{mM})$ was added into each well to initiate the redox reactions. At each time point, $0.02 \mathrm{~mL}$ of $5,5^{\prime}-$ dithiobis(2-nitrobenzoic acid) (DTNB; $2 \mathrm{mM}$ ) was added, which immediately consumed all the remaining DTT to form a yellow product, 2-nitro-5-thiobenzoic acid (TNB; Fig. S1 in the Supplement). DTNB was added in excess (10 times) of DTT for the rapid and complete consumption of the remaining DTT. The initial DTT concentration was determined in order to maintain an eventual consumption of around $50 \%$ (Fig. S2c, d) for PAH-derived SOA. TNB was quantified by the light absorption at a wavelength of $412 \mathrm{~nm}$, which was further converted to the DTT amount by calibration curve (Fig. S2b) in order to obtain the DTT decay rate. The reaction was quenched by adding DTNB at different wells at different times (all containing the same initial mixture), allowing for quantification of the DTT decay rate over a 30 min time interval (every $5 \mathrm{~min}$ for the first $10 \mathrm{~min}$ and then every $10 \mathrm{~min}$ ). Blank control and the calibration curve for DTT quantification are shown in Fig. S2. SOA methanol extractions were blown off by various extents in order to assess whether the loss of volatile compounds along with the $\mathrm{N}_{2}$ blow-off procedure affects the DTT activity of SOA (Fig. S3). Here, we used the total DTT decay rate, DTT $\left(\mu \mathrm{M}\right.$ DTT $\left.\min ^{-1}\right)$, to report the total oxidative capacity, as well as the mass normalized DTT decay rate, DTT $\mathrm{m}$ (pmol DTT $\min ^{-1} \mu \mathrm{g}^{-1}$ organics), to report the OP (Charrier et al., 2016; Jiang et al., 2017; Xiong et al., 2017). Detailed information about the chemicals used in this assay is shown in Sect. S1 in the Supplement.

\subsection{Quantification of peroxides in SOA}

Quantification of total peroxides in the four types of SOA was conducted using the iodometric-spectrophotometric method, which quantifies total aerosol peroxides in all three forms $\left(\mathrm{H}_{2} \mathrm{O}_{2}\right.$, $\mathrm{ROOH}$, ROOR; Banerjee and Budke, 1964; Docherty et al., 2005):

$\mathrm{ROOR}+2 \mathrm{I}^{-}+2 \mathrm{H}^{+} \rightarrow 2 \mathrm{ROH}+\mathrm{I}_{2}$,

$\mathrm{I}_{2}+\mathrm{I}^{-} \rightarrow \mathrm{I}_{3}^{-}$,

where $\mathrm{I}^{-}$is oxidized to $\mathrm{I}_{2}$ by peroxides under acidic conditions, and then complexes with remaining $\mathrm{I}^{-}$to form $\mathrm{I}_{3}^{-}$, a compound with brown color detected spectrophotometrically at a wavelength of $470 \mathrm{~nm}$. The concentration of each SOA solution was first adjusted to $5 \mathrm{mM} ; 0.02 \mathrm{~mL}$ of potassium iodide solution $\left(1 \mathrm{~g} \mathrm{~mL}^{-1}\right.$, KI dissolved in DI water), which provided the $\mathrm{I}^{-}$in Reaction (R1), and $0.02 \mathrm{~mL}$ of formic acid
(Sigma-Aldrich, $\geq 95 \%$ ), which maintained the acidity, were added to $0.16 \mathrm{~mL}$ of the SOA solution in each well of a 96well UV plate. The plate was immediately sealed and incubated for $1 \mathrm{~h}$ following the same procedures as in the DTT assay, and the UV-Vis absorbance was measured at $470 \mathrm{~nm}$. After testing for the sensitivities of various peroxides in KI assay (Fig. S4), and following the previous work by Kautzman et al. (2010), benzoyl peroxide (Sigma-Aldrich, $\geq 98 \%$ ) was chosen to represent peroxides in NSOA and used as standards for mass calibration in this study. All values are reported as mass fraction of peroxides in the total SOA.

\subsection{Heterogeneous oxidation}

Heterogeneous oxidation of NSOA was conducted by first cutting a filter with freshly collected NSOA into halves (within 3 days of flow tube synthesis and stored at $-20^{\circ} \mathrm{C}$ ). One half of the filter was placed in a sealed container, and an $\mathrm{O}_{3}$ stream $\left(\sim 3 \mathrm{ppm}\right.$, from the previously mentioned $\mathrm{O}_{3}$ generator) was passed through the filter at a flow rate of $0.2 \mathrm{~L} \mathrm{~min}^{-1}$. The other half of the filter was treated in parallel with a $0.2 \mathrm{~L} \mathrm{~min}^{-1}$ flow of $\mathrm{N}_{2}$ over the same time intervals, to account for evaporation and/or decomposition of SOA components at room temperature. Three sets of experiments were conducted with exposure times of 1,12 , and $24 \mathrm{~h}$ where the $\mathrm{O}_{3}$ exposure can be determined by

$\mathrm{O}_{3}$ exposure $=\int_{0}^{t}\left[\mathrm{O}_{3}\right] \mathrm{d} t=\left\langle\mathrm{O}_{3}\right\rangle_{t} \times t$,

where $\left\langle\mathrm{O}_{3}\right\rangle_{t}$ is the time averaged $\mathrm{O}_{3}$ concentration at a total flow rate of $0.2 \mathrm{~L} \mathrm{~min}^{-1}$. The DTT activity of each $\mathrm{O}_{3}-$ exposed aerosol sample was normalized to that of the corresponding $\mathrm{N}_{2}$ exposure group. Changes in organic carbon mass on NSOA filters exposed to $\mathrm{O}_{3} / \mathrm{N}_{2}$ for 1,12 , and $24 \mathrm{~h}$ were also monitored with a thermal optical organic carbon / elemental carbon (OC / EC) aerosol analyzer instrument (Sunset Laboratory Inc., Tigard, OR, USA). OC / EC content was measured following the IMPROVE OC/EC protocol (Chow et al., 1993). Blanks were measured before each run and subtracted from the sample measurements.

\subsection{Chromatographic separation of NSOA}

To identify the relative contributions of monomers and oligomers in NSOA and phenanthrene SOA (PSOA) to DTT activity, the SOA extract was separated using ultrahigh-performance liquid chromatography (UHPLC), and analyzed using electrospray ionization/ion mobility/timeof-flight mass spectrometry (ESI/IMS-TOF MS, TOFWERK, Switzerland; hereafter referred to as IMS-TOF). SOA methanol extract $\left(30 \mathrm{~g} \mathrm{~L}^{-1}\right)$ was separated on a reverse-phase column (ZORBAX Eclipse Plus C18, Agilent, USA) with an initial mobile phase of $90 \%$ DI water and $10 \%$ HPLC methanol at a flow rate of $0.15 \mathrm{~mL} \mathrm{~min}^{-1}$ (1290 Infinity II, 
Agilent, USA). The ratio of water to methanol was gradually adjusted from $9: 1$ to $1: 9$ between 25 and 30 min. Separation temperature was set to $30^{\circ} \mathrm{C}$ with a pressure setting of 150 bar. The outlet flow was regulated using LC-MS post column flow splitters (Supelco, Sigma-Aldrich, USA) at a ratio of $30: 1$. The major flow was collected in two different fractions: the first fraction was collected between 6 and $14 \mathrm{~min}$, and the second fraction was collected between 14 and $33 \mathrm{~min}$ for NSOA (3-17 and 17-28 min for PSOA). DTT assay was conducted on each fraction to assess their OPs. The minor flow injected into IMS-TOF was controlled at $5 \mu \mathrm{L} \mathrm{min}^{-1}$ for mass spectrometric analysis in the negative mode.

A deactivated fused silica capillary $(360 \mu \mathrm{m}$ OD, $50 \mu \mathrm{m}$ ID, $50 \mathrm{~cm}$ length, New Objective, Woburn, MA, USA) was used as the sample transfer line between the UHPLC and the IMS-TOF. The ESI source was equipped with an uncoated SilicaTip Emitter ( $360 \mu \mathrm{m}$ OD, $50 \mu \mathrm{m}$ ID, $50 \mu \mathrm{m}$ tip ID, New Objective, Woburn, MA, US). Charged SOA droplets generated from the tip of the emitter were transferred through a desolvation region by a $1 \mathrm{~L} \mathrm{~min}^{-1} \mathrm{~N}_{2}$ flow at room temperature, and ions produced from the evaporated droplets were introduced into the drift tube for ion mobility separation. The IMS drift voltage was set to $-1.2 \mathrm{kV}$ for the negative mode. The separation temperature was set to $80 \pm 1{ }^{\circ} \mathrm{C}$ with an operation pressure setting of $1.2 \mathrm{bar}$ for the whole mass spectrometer. After separation in the ion mobility region, the ion $\mathrm{m} / \mathrm{z}$ is measured by high-resolution time-of-flight mass spectrometry within an $\mathrm{m} / \mathrm{z}$ range of 40 to 800 . Resolution $\left(\mathrm{m} / \mathrm{d} m_{50}\right)$ of the time-of-flight mass spectrometer is typically 3500 4000 FWHM at $m / z 250$ (Groessl et al., 2015; Krechmer et al., 2016). Spectra recording and data processing of the current study were performed using routines written in Igor Pro (6.37, Wavemetrics, OR, USA): "Acquility" (version 2.1.0, http://www.tofwerk.com/acquility) for raw data acquisition and "Tofware" (version 2.5.3, www.tofwerk.com/tofware) for post-processing.

\section{$2.7{ }^{1}$ H NMR spectroscopy}

${ }^{1} \mathrm{H}$ NMR spectroscopy was used to further investigate the mechanism behind the OP reduction upon mixing specific organics and transition metals (Simpson et al., 2011; Simpson and Simpson, 2014; Smith and van Eck, 1999). NMR measurements were performed on a Bruker Avance III NMR spectrometer (11.7 T), equipped with a four-channel liquid state $\left({ }^{1} \mathrm{H},{ }^{13} \mathrm{C},{ }^{15} \mathrm{~N},{ }^{2} \mathrm{H}\right)$ inverse detection probe (QXI) fitted with an actively shielded $Z$ gradient. Typical parameters used for $1-\mathrm{D}{ }^{1} \mathrm{H}$ experiments were a $9.5 \mu{ }^{1} \mathrm{H}$ pulse, $64 \mathrm{k}$ acquisition points, and $14 \mathrm{ppm}$ spectral width; eight transients were collected, with a total of $5.7 \mathrm{~s}$ between scans. Before NMR analysis, each sample was dissolved into deuterium oxide $\left(\mathrm{D}_{2} \mathrm{O}\right.$, Cambridge Isotope Laboratories, $\left.99.96 \%\right)$ and dimethyl sulfoxide (DMSO, Fisher Scientific, 99.9\%) at a ratio of $9: 1$. Here we used $\mathrm{D}_{2} \mathrm{O}$ as a lock reagent by suppressing it through pre-saturation.
In order to monitor the duration for the nuclear spin magnetization returning to an equilibrium state, NMR relaxation times T1 (longitudinal direction) and T2 (transverse direction) were analyzed. $\mathrm{T} 1$ of the sample was measured through the standard inversion recovery experiment. The delay periods used for T1 measurements ramped from 0.001 to $15 \mathrm{~s}$ in 16 increments with a delay of $60 \mathrm{~s}$ between scans, which represented $>5 \times \mathrm{T} 1$ time to permit full signal recovery. For each delay period, 16 transients were collected. The T2 of the sample was measured through the standard Carr-PurcellMeiboom-Gill (CPMG) sequence. The delay periods used for T2 measurements ramped from 1.2 to $614 \mathrm{~ms}$ in 16 increments with a delay of $60 \mathrm{~s}$ between scans, which represented $>5 \times \mathrm{T} 1$ time to permit full signal recovery. For each delay period, 16 transients were collected. A total of 16 free induction decays were collected for each of the relaxation experiments, and relaxation time calculations were done using Bruker Dynamics Centre (v2.4.5) with mono-exponential fitting functions (Eqs. 3 and 4 below).

$$
\begin{aligned}
& f(t)=I_{0} \times\left[1-2 e^{-t / \mathrm{T} 1}\right] \\
& f(t)=I_{0} \times e^{-t / \mathrm{T} 2}
\end{aligned}
$$

Equations (2) and (3) are the fitting functions for T1 and T2, respectively, where $I_{0}$ is the thermal equilibrium state of the overall proton nuclear spin magnetization and $t$ is the variable delay time.

All the ${ }^{1} \mathrm{H}$ NMR spectra were collected using TopSpin (Bruker, v3.2). Post-NMR data processing was conducted in MestReNova (Mestrelab Research, v11.0.4) and Origin (OriginLab, v9).

\subsection{Statistical analysis}

Data in this study were interpreted as mean \pm standard error of the mean (SEM, $n=3$ ), and significance analyses among DTT activities were performed by Student's $t$ test with a $95 \%$ confidence interval. A statistical value of $p<0.05$ was considered significant.

\section{Results and discussion}

\subsection{DTT activity of laboratory-generated SOA}

Here, we chose two types of SOA derived from PAHs, naphthalene and phenanthrene, as the model SOA systems. The OP of NSOA has been shown to be the highest among various types of SOA previously studied (Tuet et al., 2017a, b). At the same time, both NSOA and PSOA contain quinones which are known to be highly redox active and exhibit high OP (Cho et al., 2004; McWhinney et al., 2013). As a comparison, $\alpha$-pinene and limonene SOA from ozonolysis were chosen to represent biogenic SOA derived from monoterpenes. Experimental conditions and SOA yield information are summarized in Table 1. 
Table 1. Flow tube experimental conditions.

\begin{tabular}{llrrr}
\hline Compound & Reaction $^{\mathrm{a}}$ & $\begin{array}{r}\Delta \mathrm{HC} \\
\mathrm{ppb}\end{array}$ & $\begin{array}{r}\mathrm{Y}^{\mathrm{b}, \mathrm{c}} \\
\%\end{array}$ & $\begin{array}{r}\mathrm{RH} \\
\%\end{array}$ \\
\hline Limonene & ozonolysis & $251 \pm 23$ & $25 \pm 3.9$ & $14 \pm 1$ \\
$\alpha$-Pinene & ozonolysis & $304 \pm 17$ & $19 \pm 4.2$ & $14 \pm 1$ \\
Naphthalene & photooxidation & $6436 \pm 402$ & $28 \pm 6.7$ & $57 \pm 5$ \\
Phenanthrene & photooxidation & $4050 \pm 578$ & $12 \pm 2.6$ & $57 \pm 5$ \\
\hline
\end{tabular}

${ }^{\mathrm{a}}$ Temperature in all experiments is around room temperature $\left(22-25^{\circ} \mathrm{C}\right) \cdot{ }^{\mathrm{b}} \mathrm{SOA}$ mass yields were calculated without particle wall loss correction. ${ }^{\mathrm{c}}$ SOA density in this study was assumed to be $1.25 \mathrm{~g} \mathrm{~cm}^{-3}$ for monoterpene SOA (Shilling et al., 2009), and $1.55 \mathrm{~g} \mathrm{~cm}^{-3}$ for PAHs SOA (Chan et al., 2009).

The mass-normalized DTT decay rate, $\mathrm{DTT}_{\mathrm{m}}$, was applied here for OP evaluation (Fig. 2). Similar $\mathrm{DTT}_{\mathrm{m}}$ has been reported for NSOA, with values of $118 \mathrm{pmol} \mathrm{min}^{-1} \mu \mathrm{g}^{-1}$ by McWhinney et al. (2013) and $110 \mathrm{pmol} \mathrm{min}^{-1} \mu \mathrm{g}^{-1}$ by Tuet et al. (2017b) for NSOA generated from chamber photooxidation under dry conditions. The $\mathrm{DTT}_{\mathrm{m}}$ of $\alpha$-pinene SOA of $19.1 \pm 2.5 \mathrm{pmol} \mathrm{min}^{-1} \mu \mathrm{g}^{-1}$ in this study is also consistent with those reported by Tuet et al. (2017b) and Jiang et al. (2017). The similar values among the different studies highlight the reproducibility of results from the DTT assay. To the best of our knowledge, the OP of PSOA and limonene SOA from this study are the first ones reported in the literature. Both SOA values derived from PAHs yield a higher OP than the two types of monoterpene SOA. The similarities in OP between limonene and $\alpha$-pinene SOA (cyclic monoterpenes) and between naphthalene and phenanthrene SOA (PAHs) observed in this study further confirm the hypothesis proposed by Tuet et al. (2017b) that the intrinsic OP of SOA is closely related to the molecular skeleton of the precursor.

One of the reasons for the high OP exhibited by PAHderived SOA is the abundance of redox-active quinone moieties in SOA compounds (Lee and Lane, 2009). The cytotoxic and carcinogenic effects from quinone-like compounds are well recognized in the field of biochemistry (Bolton et al., 2000; Valavanidis et al., 2005), and the toxicity of PM has been attributed to the presence of quinones. Charrier and Anastasio (2012) have found the OP of several quinones are comparable to transition metals in ambient particles. The importance of quinone-like components to OP was also evaluated by examining the changes in DTT activity in response to the presence of 2,4-dimethylimidazole, which has been shown to be the co-catalyst of the quinone redox cycle (Jiang et al., 2017). However, McWhinney et al. (2013) quantified three quinones in NSOA using GC/MS and found that these quinones can only account for $30 \%$ of the total NSOA DTT response. The remaining DTT activity may arise from other quinone-like compounds that have not been identified, or from other oxidation products in NSOA. Given this knowledge gap, we examine the potential roles of peroxides, oligomers and other more oxygenated products that may explain the high-DTT activities of NSOA in the next sections.

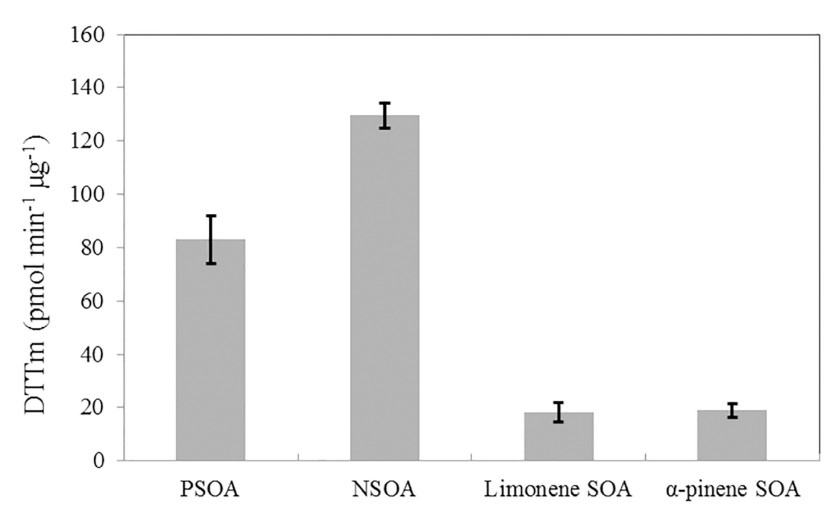

Figure 2. $\mathrm{DTT}_{\mathrm{m}}\left(\mathrm{pmol} \mathrm{min}^{-1} \mu \mathrm{g}^{-1}\right)$ for SOA formed from various types of hydrocarbons (phenanthrene, naphthalene, limonene, and $\alpha$-pinene). Each measurement was conducted in triplicates, and the error bar represents the standard error of the mean (SEM).

\subsection{OP contribution from peroxides}

One of the main hypothesis in this study is that organic peroxides contribute to OP. Organic peroxides have been identified to be major components in both laboratory and ambient OA (Jokinen et al., 2014; Lin et al., 2016; Surratt et al., 2010; Zhang et al., 2015, 2017). They can play important roles in forming high MW oligomers (Docherty et al., 2005) and highly oxygenated molecules (Mentel et al., 2015). Recent studies have shown that peroxides may also be important for OP. Kramer et al. (2016) suggested that isoprene-derived hydroxyhydroperoxide (ISOPOOH) is an essential contributor to the OP of isoprene SOA, consistent with the results of bulk peroxide measurements using 4-nitrophenylboronic acid assay (NPBA assay) by Jiang et al. (2017). Since peroxides have been proposed to be a major component in NSOA (Kautzman et al., 2010), it is essential to determine whether or not these peroxides can account for the remaining OP contribution (McWhinney et al., 2013).

Here we compare the NSOA and $\alpha$-pinene SOA systems to determine the role of peroxides in OP. The KI assay is known to be sensitive to all types of SOA peroxides (ROOR, $\mathrm{ROOH}$, and $\mathrm{HOOH}$; Banerjee and Budke, 1964), and we confirmed its sensitivity by conducting calibrations with four different peroxides (Fig. S4). Similar KI response factors were observed with hydrogen peroxide, cumene hydroperoxide, tert-butyl peroxide, and benzoyl peroxide. Since it is likely that the peroxides in NSOA with one aromatic ring are mostly in the form of ROOR (Kautzman et al., 2010), we used benzoyl peroxide as the mass calibration standard. The mass fraction of peroxides and $\mathrm{DTT}_{\mathrm{m}}$ of each SOA system are shown in Table 2. A high percentage of peroxide (40-100\%) was observed in $\alpha$-pinene SOA, which was consistent with the results $(47 \%)$ in the study by Docherty et al. (2005). Meanwhile, a very low percentage of peroxides $(<3 \%)$ was found in NSOA system, a result that is inconsis- 
Table 2. SOA peroxide content and OP.

\begin{tabular}{lrr}
\hline Organics & Peroxide percentage & $\begin{array}{r}\mathrm{DTT}_{\mathrm{m}} \\
\%\end{array}$ \\
\hline Naphthalene SOA & $<3$ & $100-129$ \\
$\alpha$-Pinene SOA & $40-100$ & $10-20$ \\
Benzoyl peroxide & 100 & 37 \\
\hline
\end{tabular}

tent with previous work ( $>20 \%$ ) by Kautzman et al. (2010). The difference in measured peroxide content is most likely due to the difference in the UV light source. Kautzman et al. (2010) and McWhinney et al. (2013) used $\mathrm{H}_{2} \mathrm{O}_{2}$ photolysis under black lights $(\sim 350 \mathrm{~nm})$, whereas in our study $254 \mathrm{~nm}$ UV lamps were used to photolyze $\mathrm{O}_{3}$ and generate $\mathrm{O}\left({ }^{1} \mathrm{D}\right)$. Organic peroxides in SOA are known to be photolabile (Banerjee and Budke, 1964; Krapf et al., 2016; Wang et al., 2011) and had likely decomposed rapidly under the shorter UV wavelengths used in our studies. Despite the differences in light conditions and peroxide content, the $\mathrm{DTT}_{\mathrm{m}}$ measured for NSOA in this study is consistent with those measured in two separate studies (McWhinney et al., 2013; Tuet et al., 2017b). Also, the DTT $\mathrm{m}_{\mathrm{m}}$ of NSOA was found to be significantly higher than that of $\alpha$-pinene SOA, which contains a large fraction of peroxides. Therefore, from our work, there is no evidence showing that peroxides contribute significantly to the high $\mathrm{DTT}_{\mathrm{m}}$ observed in NSOA. Even if organic peroxides were present at a mass fraction of around $20 \%$, as reported by Kautzman et al. (2010), we expect these peroxides would react with DTT at a similar rate as benzoyl peroxide, which has a similar structure to that of the proposed peroxides. The DTT $m$ of benzoyl peroxide (ROOR-type) is 37 pmol $\mathrm{min}^{-1} \mu \mathrm{g}^{-1}$ (Fig. 3), which is around 3 times lower than the $\mathrm{DTT}_{\mathrm{m}}$ of NSOA. It should also be noted that organic hydroperoxides are the major OP contributors for biogenic SOA, such as isoprene and monoterpene SOA (Jiang et al., 2017). One of the potential mechanisms is the formation of hydroxyl radicals from the decomposition of organic hydroperoxides in water (Tong et al., 2016). For the NSOA system, our results suggest that other non-peroxide species are likely to serve as major contributors to OP.

\subsection{OP of oligomers in NSOA}

Atmospheric OA also undergoes extensive oligomerization, forming high MW compounds that have profound impacts on SOA physicochemical properties (Hallquist et al., 2009; Rudich et al., 2007; Trump and Donahue, 2014; Wang et al., 2011). Laboratory photooxidation of aromatic compounds produces a substantial fraction of oligomers in the SOA (Kalberer et al., 2004) and these oligomers may be highly functionalized (Gao et al., 2004; Tolocka et al., 2004). IMSTOF analysis reveals that a substantial fraction of the signals in NSOA and PSOA are located in the high $m / z$ range, which are associated with high MW oligomeric products. Since pre-

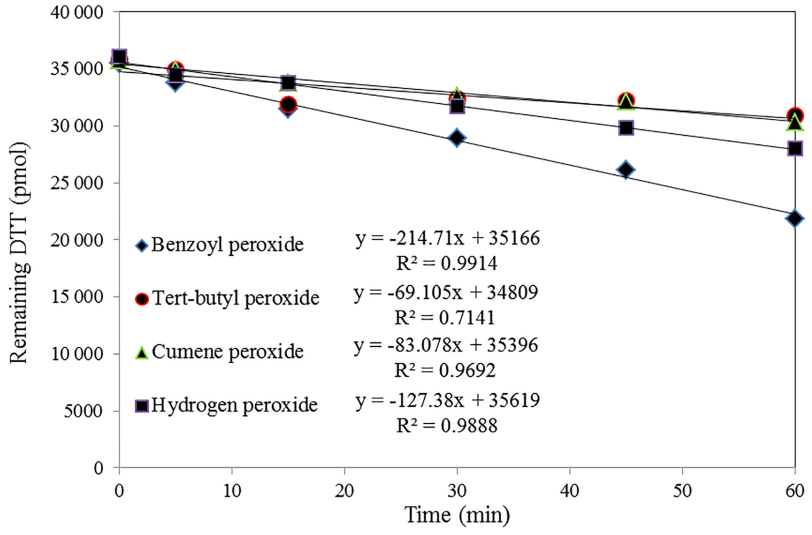

Figure 3. DTT activity of various types of peroxides (hydrogen peroxide, cumene peroxide, tert-butyl peroxide, benzoyl peroxide). With the same initial concentration of peroxide $(120 \mu \mathrm{M})$, benzoyl peroxide has the highest DTT activity (converted to $\mathrm{DTT}_{\mathrm{m}}$ of 37 pmol $\min ^{-1} \mu \mathrm{g}^{-1}$ ).

vious studies have largely focused on monomeric quinones (such as 1,2-naphthoquinone or 9,10-phenanthrenequinone), the contribution of high MW products to OP have not been studied and may explain the "missing" OP contributors.

To evaluate OP of high MW products in NSOA and PSOA, solutions of SOA extract were separated in a $\mathrm{C} 18$ reversephase column into two major fractions. As shown in Fig. 4, when analyzed by IMS-TOF, the first fraction was found to contain relatively higher signals at $\mathrm{m} / \mathrm{z}$ associated with monomers, and the second fraction contain products with higher signals located in a higher $m / z$ range. It should be noted that complete separation could not be achieved in this work. Other techniques, such as size-exclusion chromatography (Di Lorenzo and Young, 2016; Di Lorenzo et al., 2017), may yield better separation based on molecular weights, but may not be able to resolve compounds in the relatively low molecular weight range in the current study. Nonetheless, the first fraction can be qualitatively described as a "monomerrich" fraction, and the second fraction can be regarded as an "oligomer-rich" fraction (Figs. 4, 5a, b). The DTT assay was then conducted on both of the original SOA solution as well as the two separated fractions. Since the amount of organic material in each fraction is not known, we use the total DTT activity $\left(\mathrm{DTT}_{\mathrm{t}}\right.$, in $\left.\mu \mathrm{M} \mathrm{min}^{-1}\right)$ to qualitatively compare the oxidative capacities of the two fractions.

As shown in Fig. 5, both the monomer-rich and oligomerrich fractions are reactive towards DTT. Compared to the $\mathrm{DTT}_{t}$ of NSOA before LC separation, relative DTT $\mathrm{t}_{t}$ of monomer-rich fraction and the oligomer-rich fraction were $16 \pm 3$ and $56 \pm 10 \%$, respectively (Fig. 5c). For PSOA, relative $\mathrm{DTT}_{\mathrm{t}}$ from monomer-rich fraction and oligomer-rich fraction were $40 \pm 8$ and $50 \pm 5 \%$, respectively (Fig. 5d). In both systems, the oligomer-rich fraction caused a more rapid decay in DTT than the monomer-rich fraction even with a 
(a)

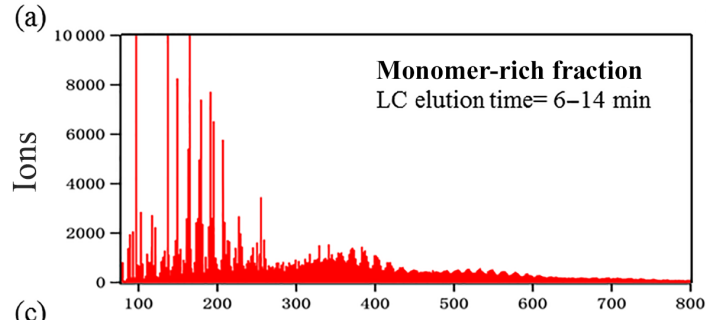

(c)

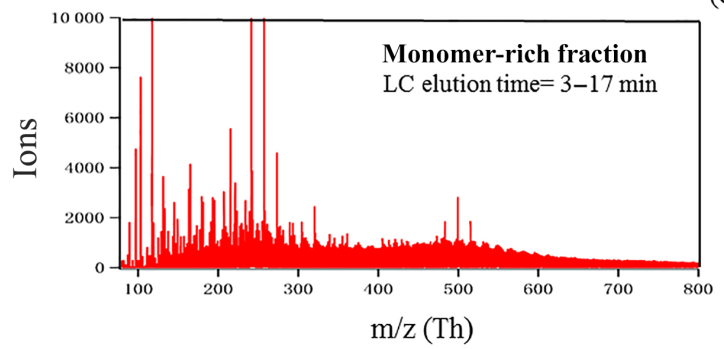

(b)

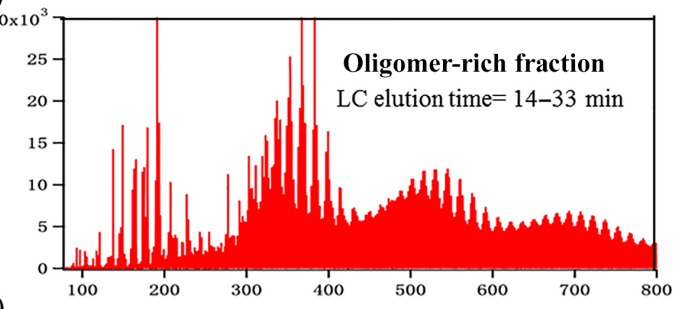

(d)

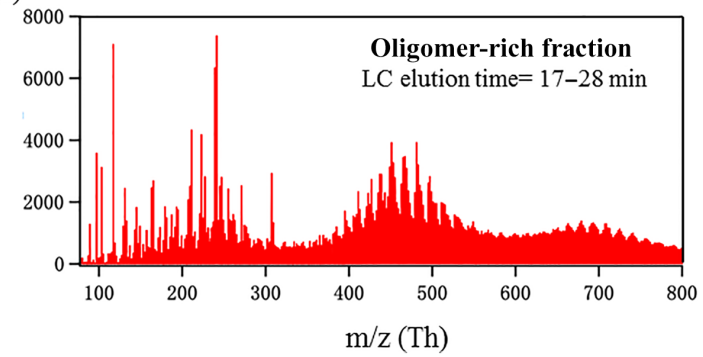

Figure 4. IMS-TOF mass spectra for (a) monomer-rich fraction and (b) oligomer-rich fraction in NSOA, and for (c) monomer-rich fraction and (d) oligomer-rich fraction in PSOA. During a total of 46 min elution, the majority of NSOA monomers eluted at 6-14 min, and most of the oligomers eluted at 14-33 min. For PSOA system, the majority of monomers eluted at 3-17 min, and most of the oligomer-rich fraction eluted at $17-28 \mathrm{~min}$.

(a)

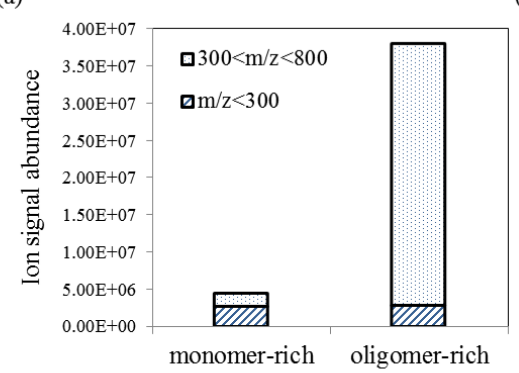

(c)

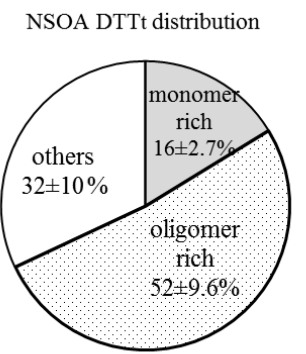

(b)

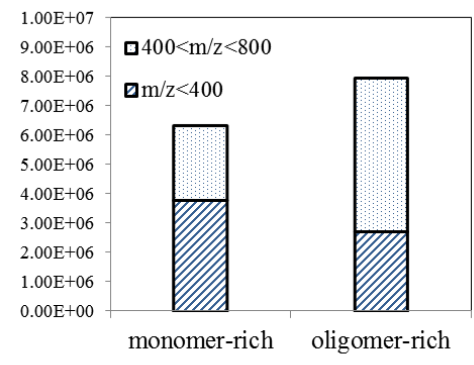

(d)

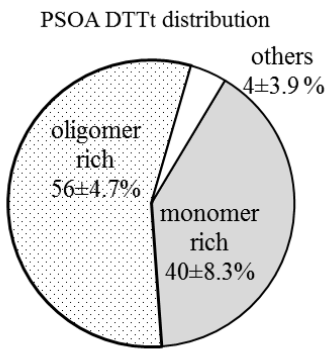

Figure 5. Sum of ion signals for monomers and oligomers in monomer-rich fraction and oligomer-rich fraction for NSOA (a) and PSOA (b)

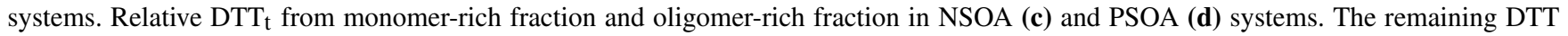
activity (others, white) is attributed to residual SOA fractions that did not clearly elute out.

lower summed ion signal of low MW constituents (Fig. 5a, b for NSOA and PSOA, respectively). These qualitative results suggest that while the current focus of health studies has been on monomeric quinones, other higher-MW products may be important for the OP of NSOA and PSOA. Specific molecular characteristics of these high MW OP contributors are currently unknown, and understanding them will be the subject of future research. It is very likely that the oligomers also contain redox-active quinone functional groups, such as those formed on the surface of oxidized soot (Antiñolo et al., 2015), and are therefore important for OP. 


\subsection{OP from heterogeneous oxidation}

In addition to its complexity, the composition of SOA is also highly dynamic and evolves upon atmospheric oxidation (Jimenez et al., 2009). Heterogeneous oxidation in the particle phase is one of the major pathways in aerosol aging (George and Abbatt, 2010; Rudich et al., 2007) and can increase oxygen content during the functionalization processes. McWhinney et al. (2013) attributed $21 \%$ of the NSOA's DTT activity to two quinone isomers (1,2-NQN and 1,4-NQN) in NSOA while finding a higher DTT contribution $(30 \%)$ when they took 5-hydroxy-1,4-naphthoquinone (5-OH-1,4-NQN) into consideration. Thus, we expect that oxygenated derivatives produced upon heterogeneous oxidation may also contribute to the OP of SOA, and the OP of SOA could be enhanced by heterogeneous oxidation.

We first examined the changes in OP with additional functional groups in known organic compounds. As shown in Fig. 6, two pairs of organic compounds in NSOA were chosen: 1,4-NQN and 5-OH-1,4-NQN were used to study quinone-like compounds, while naphthol (NPL) and 1,3dihydroxy naphthalene (1,3-DHN) were used to compare phenol-like compounds. The $\overline{\mathrm{OS}} \mathrm{c}$ of those four components were calculated (Kroll et al., 2011), as shown in Fig. 6. Our results demonstrated a higher $\mathrm{DTT}_{\mathrm{m}}$ for standards with higher oxidation states. For each addition of an $\mathrm{OH}$ group to the selected molecule, the OP increases. OP of an aromatic compound is therefore shown here to be associated with its degree of oxygenation and is demonstrated here fundamentally using individual organic compounds.

More broadly, oxidation also increases the degree of oxygenation in the bulk aerosol phase, and increases OP. Here we conducted heterogeneous oxidation by exposing filtercollected SOA to $\mathrm{O}_{3} / \mathrm{N}_{2}$ with the same flow rate. The $\mathrm{N}_{2}$ exposure group is used as the control group in order to isolate the effects of evaporation and/or decomposition at room temperature from those of heterogeneous $\mathrm{O}_{3}$ oxidation. For each of the exposure $(1,12,24 \mathrm{~h})$, the $\mathrm{DTT}_{\mathrm{t}}$ of $\mathrm{O}_{3}$ exposure group was normalized by the DTT $\mathrm{T}_{\mathrm{t}}$ of the corresponding $\mathrm{N}_{2}$ exposure group (Fig. 7a). OC loss was determined by thermal optical OC / EC analysis, and was observed to be 17 and $13 \%$ for the $\mathrm{O}_{3}$ and $\mathrm{N}_{2}$ exposure groups after $24 \mathrm{~h}$, respectively (Fig. 7b). Generally, DTT $\mathrm{t}_{\mathrm{t}}$ of NSOA filter under $\mathrm{O}_{3}$ exposure was higher than that of $\mathrm{N}_{2}$ exposure. The study of Antiñolo et al. (2015) also showed an increased redox activity of soot accompanied by an increased amount of oxygenated derivatives (quinone) under heterogeneous oxidation. However, the enhanced oxidative capacity from heterogeneous ozonolysis appeared to decrease with longer exposure to $\mathrm{O}_{3}$ (Fig. 7a), which we hypothesize may result from functionalization as well as fragmentation of organic molecules during heterogeneous oxidation (Kroll et al., 2009). This can be further confirmed with the observed changes in the different OC fractions, as shown in Fig. S5. Within the $24 \mathrm{~h}$ exposure, the volatile fractions ( $\mathrm{OC} 1$ and $\mathrm{OC} 2$ ) of the $\mathrm{O}_{3}$ exposed group

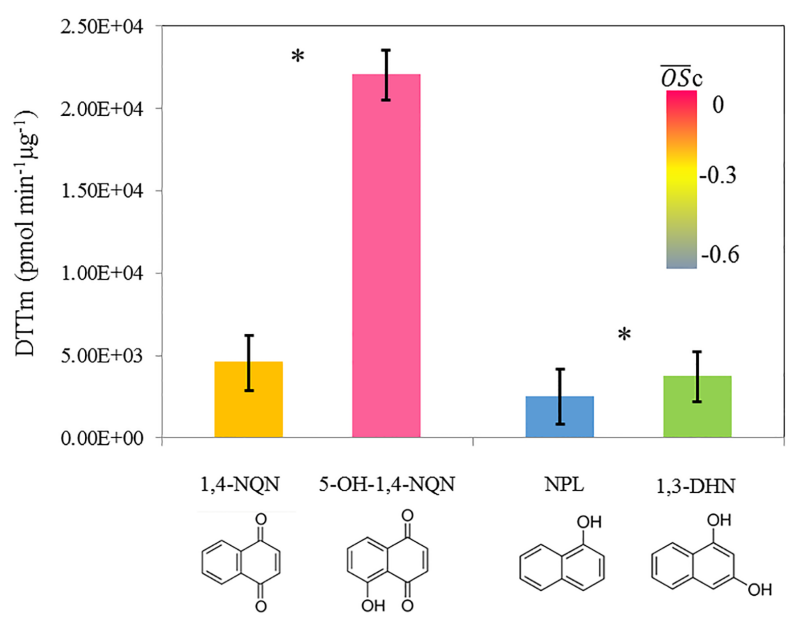

Figure 6. $\mathrm{DTT}_{\mathrm{m}}$ for two selected pairs of oxygenated derivatives in NSOA system (1,4-NQN vs. 5-OH 1,4-NQN and NPL vs. 1,3$\mathrm{DHN})$. Averaged carbon oxidation state $(\overline{\mathrm{OS}} \mathrm{c})$ of each component is shown in color (color scale shown on top right). Each measurement was conducted in triplicates, and the error bar here represents the SEM. The asterisk indicates significant difference between each pair of measurements at the $95 \%$ confidence level.

increased while the less volatile fractions (OC3 and OC4) decreased compared to the $\mathrm{N}_{2}$ group, which suggested the decomposition of high MW (low volatility) species into low MW (high volatility) compounds. Previous work has also shown fragmentation can play a dominant role in a late stage of heterogeneous oxidation (Kroll et al., 2011). The overall increased volatility may lead to evaporation of smaller redoxactive molecules and decrease the DTT $\mathrm{t}_{\mathrm{t}}$ compared to the $\mathrm{N}_{2}$ exposure group. It should also be noted that the $\mathrm{O}_{3}$ concentrations to which NSOA are exposed here are about 100 times higher than typical ambient levels (Finlayson-Pitts and Pitts Jr., 2000). Assuming heterogeneous oxidation mechanisms are linear and an ambient $\mathrm{O}_{3}$ concentration of $30 \mathrm{ppb}, \mathrm{O}_{3}$ exposure for 1,12 , and $24 \mathrm{~h}$ under our experimental conditions represent 4,50 , and 100 days of aging in the atmosphere, respectively. Therefore, we anticipate an overall enhancement in OP under ambient conditions. Though similar observations have been made in soot (Antiñolo et al., 2015) and diesel exhausted particles (McWhinney et al., 2013), this enhancement in OP by heterogeneous oxidation is shown here for the first time in SOA particles.

\subsection{OP changes upon mixing with $\mathrm{Cu}$}

Ambient PM forming from mixed sources is frequently composed of both organics and metals. To date, both organics (quinone) and transition metals $(\mathrm{Cu}, \mathrm{Fe}, \mathrm{Mn}$, etc.) have been shown to be redox-active (Charrier and Anastasio, 2012; Xiong et al., 2017). Metals in ambient particles can range from insoluble substances to soluble cations, leading to var- 

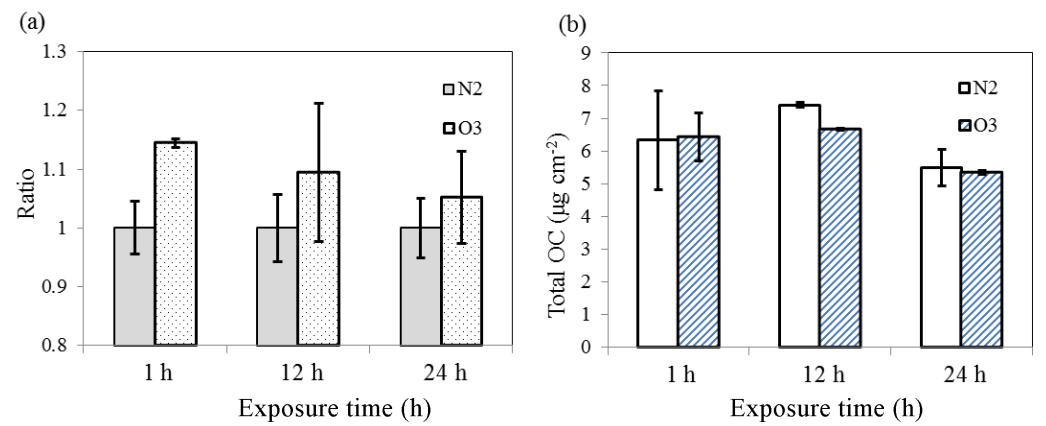

Figure 7. (a) Relative DTT for NSOA after $\mathrm{O}_{3}$ and $\mathrm{N}_{2}$ exposure. For each of the exposure duration $(1,12,24 \mathrm{~h})$, the DTT $\mathrm{t}$ of $\mathrm{O}_{3}$ exposure group was normalized by the DTT $\mathrm{T}_{\mathrm{t}}$ of the corresponding $\mathrm{N}_{2}$ exposure group. Generally, DTT $\mathrm{t}_{\mathrm{t}}$ of NSOA that underwent heterogeneous ozonolysis was higher than that of the $\mathrm{N}_{2}$ control. (b) OC / EC measurement results show total OC mass loss $\left(17\right.$ and $13 \%$ for $\mathrm{O}_{3}$ and $\mathrm{N}_{2}$ exposure, respectively) after $24 \mathrm{~h}$ exposures. Each measurement was conducted in triplicates, and the error bar represents the SEM.

(a)

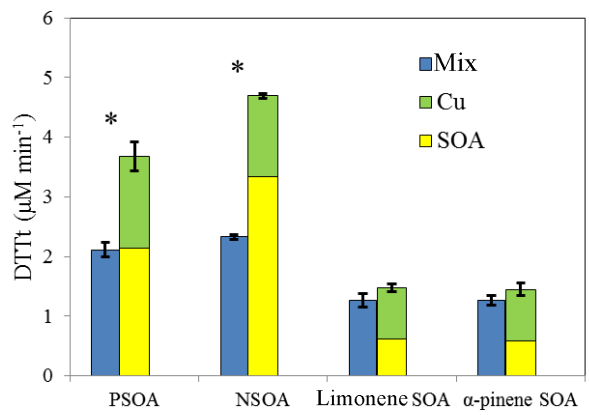

(b)

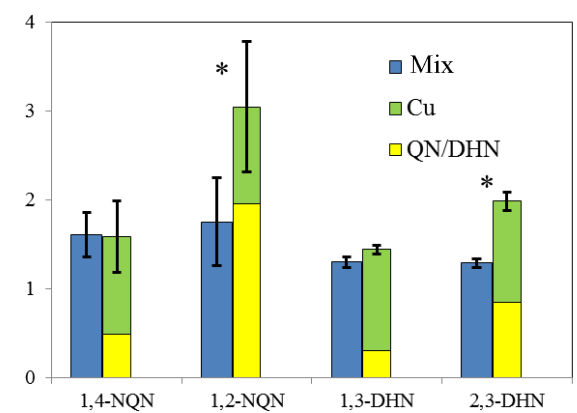

Figure 8. Significant OP depletions were observed when PSOA (43 $\pm 4 \%)$, NSOA (50 $\pm 6 \%), 1,2-\mathrm{NQN}(42 \pm 7 \%)$, and $2,3-\mathrm{DHN}$ $(35 \pm 1 \%)$ mixed with $\mathrm{Cu}$ (II). The asterisk indicates significant difference between a pair of bars at a $95 \%$ confidence level.

ious health outcomes after deposition onto the human respiratory tract (Gojova et al., 2007; Oberdörster et al., 2005).

Based on the chemical composition and the assumption that DTT activities of quinones and transition metals are additive, previous studies have attempted to reconstruct the overall OP in ambient particles based on the chemical composition (Charrier and Anastasio, 2012; Charrier et al., 2015). However, addition of a transition-metal chelator did not result in significant changes in the expression of inflammatory biomarkers (Donaldson et al., 2001), suggesting that oxidative activities from different transition metals may not be additive. In our study, significant reductions in OP were observed for PSOA $(43 \pm 4 \%)$ and NSOA $(50 \pm 6 \%)$, when they were mixed with $\mathrm{Cu}$ (II) (Fig. 8a). Conversely, no significant OP reduction was observed when $\alpha$-pinene or limonene SOA was mixed with $\mathrm{Cu}$ (II). To further investigate the cause of this reduction, we examined the OP of 1,2-NQN, 1,4NQN, 1,3-DHN, and 2,3-DHN and the effects from mixing with $\mathrm{Cu}$ (II). Significant OP reductions for 1,2-NQN ( $42 \pm 7 \%$ ) and 2,3-DHN (35 $\pm 1 \%$; Fig. 8 b) were observed, but no such changes were observed with $1,4-\mathrm{NQN}$ or 1,3DHN upon metal mixing. It should be noted that a mixture of phenanthrenequinone and $\mathrm{Cu}$ (II) did not show a signif- icant reduction in DTT activity in a study by Charrier and Anastasio (2012), while it is likely that the DTT measurements may be affected by the inefficiency of the quench regent, trichloroacetic acid (Curbo et al., 2013). Furthermore, an increased level of OP reduction was observed when an increasing amount of $\mathrm{Cu}$ (II) was mixed with the same amount of 1,2-NQN (Fig. S7). Based on the observation that OP reduction occurs only when there are neighboring oxygenated functional groups, we hypothesize that the OP reduction is related to formation of covalent bonds between the electrondeficient $\mathrm{Cu}$ (II) and the electron-donating polar functional groups. The formation of quinone-copper complexes have been demonstrated previously (Dooley et al., 1990; Klinman, 1996), and may be responsible for reducing the overall OP.

To understand the underlying mechanism, ${ }^{1} \mathrm{H}$ NMR spectroscopy was used to monitor the formation of the organic$\mathrm{Cu}$ complex. ${ }^{1} \mathrm{H}$ NMR has previously been applied to study the binding between metals and organics (Peana et al., 2015; Syme and Viles, 2006). The relaxometry (T2) of NSOA illustrated in Fig. 9 shows a decreasing trend on average for T2 relaxation time when $\mathrm{Cu}$ (II) was added to the system. Such a decrease in relaxation time indicates interactions between copper and SOA components. In general, protons adjacent 
to and within aliphatic hydroxyl groups resonate between 3 and $5 \mathrm{ppm}$, while aromatic groups and double bonds arise between 5 and $9 \mathrm{ppm}$. Before the addition of copper, NSOA $\mathrm{T} 2$ relaxation time shows a range of values consistent with a complex material with a diversity of functional groups and dynamics. After the addition of copper, both of the aliphatic hydroxyl and aromatic region showed a decrease in T2 and inherit roughly similar relaxation values. This suggested copper is able to influence a wide range of SOA components, with both structural categories (aliphatic hydroxyl and aromatic) involved in copper binding to some extent. Due to the complexity in the SOA NMR spectra, it is still currently challenging to specifically identify binding between individual NSOA components and $\mathrm{Cu}$. To further investigate the binding reactions, ${ }^{1} \mathrm{H}$ NMR measurements were made for the compounds present in NSOA, as previously mentioned, in the presence and absence of $\mathrm{Cu}$, as shown in Fig. 10. Significant interactions between $\mathrm{Cu}$ and 1,2-NQN are evidenced by the broadened peak shapes (Fig. 10a), caused by the coordination of adjacent oxygen groups with the copper ion, which has also been well documented in previous studies with similar compounds (Inoue and Gokel, 1990; Schmidt et al., 1990; Tolman, 1977). Protons proximal to the binding sites are more significantly broadened, while protons further away are less affected. Conversely, mixing of 1,4-NQN with $\mathrm{Cu}$ led to little changes in peak shape, indicating the lack of any interactions with copper, as shown in Fig. 10b. Similar phenomena were also observed with another pair of isomers (2,3-DHN and 1,3-DHN). As shown in Fig. 10c, 2,3-DHN shows a clear change in peak shape indicating that these hydroxyl moieties on adjacent carbons are very important for copper coordination. On the other hand, the 1,3-DHN structure shows very little peak broadening when mixed with copper.

Such binding evidence was further supported by NMR relaxation data (Fig. 11). As copper is paramagnetic, it is an effective relaxation agent, and protons brought into its proximity undergo faster $\mathrm{T} 1$ and $\mathrm{T} 2$ relaxation that manifest themselves as spectral broadening in 1-D NMR (Fig. 10). For the epitope maps, the largest circles indicate the least interactions with copper. For both $\mathrm{T} 1$ and $\mathrm{T} 2$ data (Fig. 11, Table $\mathrm{S} 1$ ), protons adjacent to the binding sites a and $\mathrm{f}$ (proton peak assignment based on Figs. 10a, S6) underwent significant changes in relaxation indicating the metal coordinating to the neighboring oxygen groups. Proton e changed less as it is located further away from the copper binding site. While copper has a relatively mild effect on protons $b$ and d, a significant reduction in $\mathrm{T} 1$ and $\mathrm{T} 2$ for proton $\mathrm{c}$ was observed. Such interesting phenomenon is due to the increased nuclear Overhauser effect (NOE) from the $b$ and $d$ sites. In the $a b-$ sence of binding, protons $b$ and $d$ would in part relax via NOE with protons a and e, which relax rapidly due to the copper binding. As such protons $b$ and $d$ can no longer lose magnetization via an Overhauser effect owing to a and e. Instead, they pass magnetization to position $\mathrm{c}$, which underwent an

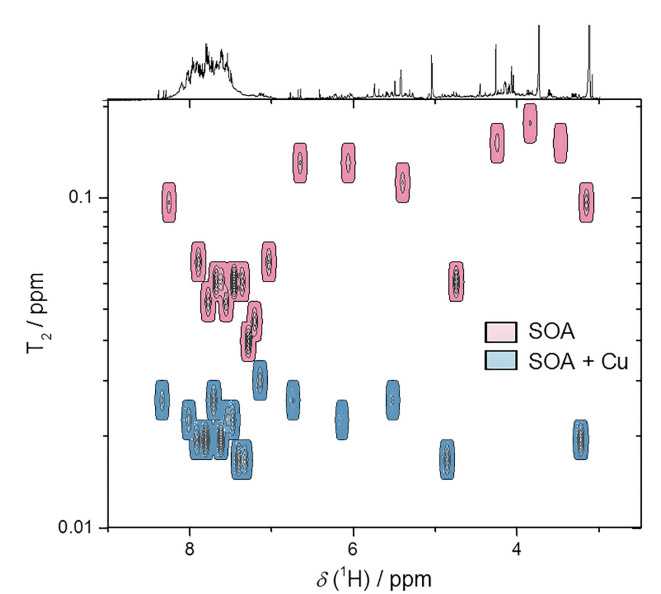

Figure 9. 2-D ${ }^{1} \mathrm{H}-\mathrm{NMR}$ T2 relaxation contour map for NSOA with (blue) and without copper (red) with 1-D NMR projections from the top. A general decreasing trend in $\mathrm{T} 2$ is observed here, which indicates interactions (binding) of $\mathrm{Cu}$ (II) with many NSOA components.

enhanced level of relaxation as a result. The NOE effect for ring systems with similar structure has also been demonstrated in several publications (Kowalewski and Maler, 2006; Rehmann and Barton, 1990). It should be noted that the increased level of OP depletion is accompanied by an increased ratio of $\mathrm{Cu}$ to 1,2-NQN (Fig. S4a), the degree of broadening in the 1-D NMR proton peaks becomes more significant (Fig. S4b), and the relaxation times $\mathrm{T} 1$ and $\mathrm{T} 2$ decrease (Fig. 11). All these observations together illustrate that the reduction of OP is proportional to the binding between $\mathrm{Cu}$ and organics, and further supports the mechanism behind $\mathrm{OP}$ depletion in the DTT assay. Based on the conclusions from the individual organic standards, the overall decrease in relaxation times for NSOA mixing with $\mathrm{Cu}$ (shown in Fig. 9) likely indicates that $\mathrm{Cu}$ (II) are binding with NSOA components, limiting the redox activities and $\mathrm{OP}$ of both the $\mathrm{Cu}$ (II) ions and the redox-active NSOA components.

\section{Implications}

Oxidative stress caused by ROS production and antioxidant consumption is one of the most commonly studied mechanisms for PM toxicity (Nel, 2005; Rhee, 2006; Manke et al., 2013). Here we performed OP evaluation of two SOA formed from PAHs (naphthalene, phenanthrene) by the DTT assay, and investigated the linkages between SOA OP and chemical composition upon various atmospheric aging processes. SOA derived from ozonolysis of monoterpenes ( $\alpha$-pinene, limonene) have a lower $\mathrm{DTT}_{\mathrm{m}}$ than that of the two SOAderived PAHs, which could be attributed to the high redoxactive quinone-like components. This is also consistent with the previous hypothesis that OP of SOA is highly dependent on the identity of its precursor (Tuet et al., 2017a). To fur- 
(a)

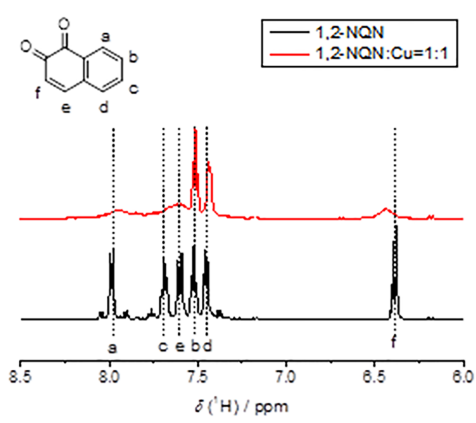

(b)

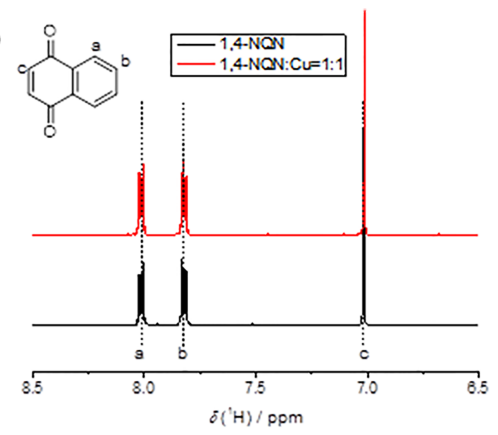

(c)

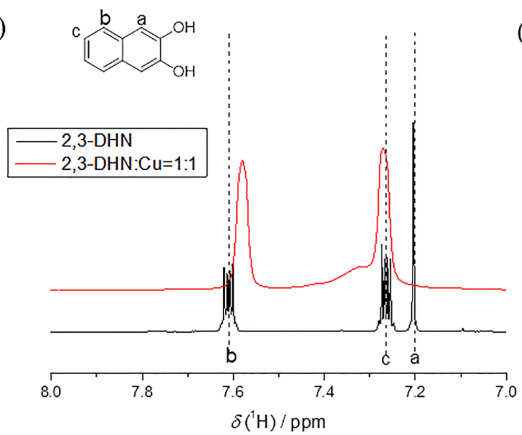

(d)

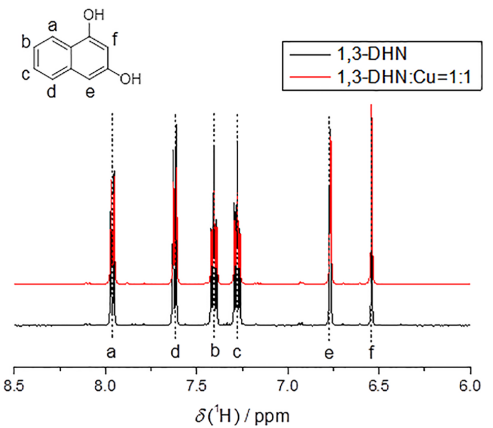

Figure 10. 1-D ${ }^{1} \mathrm{H}-\mathrm{NMR}$ spectra of (a) 1,2-NQN, (b) 1,4-NQN, (c) 2,3-DHN, and (d) 1,3-DHN, and their mixture with $1: 1$ ratio of Cu (II). Both 1,2-NQN and 2,3-DHN show the broadening of ${ }^{1} \mathrm{H}-\mathrm{NMR}$ peaks (protons at a, c, e, f and a, b, c for 1,2-NQN and 2,3-DHN, respectively) after mixing with $\mathrm{Cu}(\mathrm{II})$.
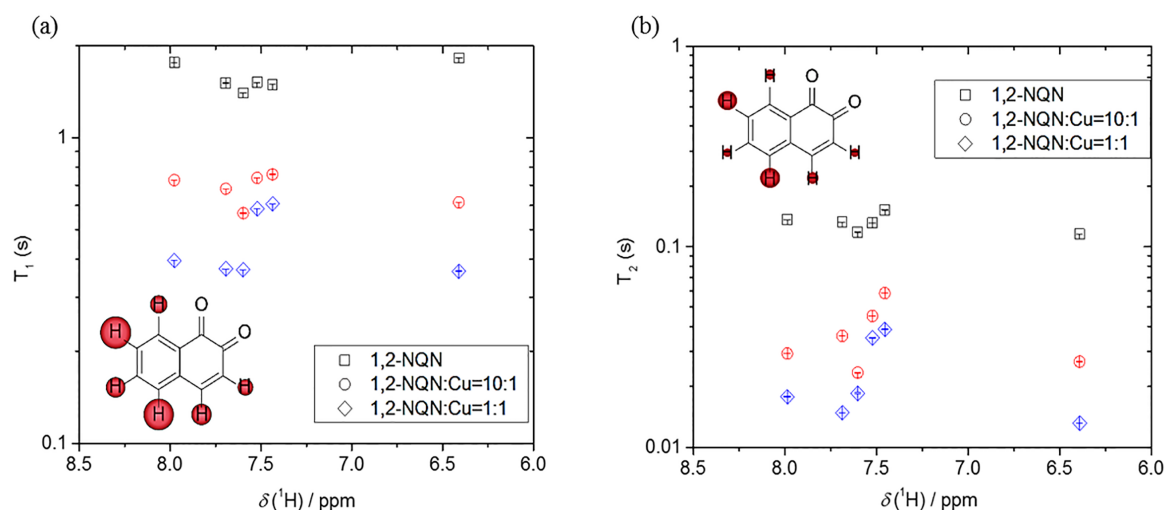

Figure 11. ${ }^{1} \mathrm{H}$ NMR relaxometry analyses for (a) T1 and (b) T2 of 1,2-NQN mixed with Cu (II) at different ratios: 1,2-NQN with no $\mathrm{Cu}$ (black), $\mathrm{Cu}$ (II): 1,2-NQN = $1: 10$ (red), and $\mathrm{Cu}$ (II): 1,2-NQN = 1:1 (blue). Both T1 and T2 decreased when Cu was introduced into the system, indicating a smaller scale of nuclear spin dynamic resulted from organic-metal binding. The molecular epitopes illustrate the influence of $\mathrm{Cu}$ (II) binding on an individual proton. A smaller sphere shadow on a proton denotes a larger relaxation influence from $\mathrm{Cu}$ (II)-organic binding.

ther link SOA OP to its chemical composition, this study also explored the possible impacts from atmospheric aging processes so as to provide mechanistic understanding for ambient observations.

Over the span of atmospheric lifetime, the mass and chemical composition of SOA can be affected by aging processes
(Kroll et al., 2009; Lim et al., 2017). The aerosol aging processes that we studied here include oligomerization, heterogeneous oxidation, and metal mixing. Apart from quinones that are well known to exhibit high OP in aerosol samples, OP contributions from peroxides in our NSOA system are likely to be insignificant. Rather, oxygenated derivatives 
were shown here to contribute greater OP than their precursors in our study of selected organic individuals, and heterogeneous oxidation of NSOA was shown to lead to greater OP as well. Moreover, DTT activities of the monomer-rich and oligomer-rich fractions in NSOA separated by liquid chromatography showed oligomers are OP contributors in SOA. While organic peroxides have been proved to be very labile components with half-lives of minutes at room temperature (Krapf et al., 2016), SOA oligomers are relatively stable and highly oxygenated with their ratio of total organic molecular weight per organic carbon weight (OM / OC) similar to that of atmospheric humic-like substances (HULIS; Altieri et al., 2008). Consistent with OP contributions from the oxygenated-component enriched HULIS fraction in ambient PM (Verma et al., 2015b), this study also shows evidence for OP contributors from atmospheric aging products of PAHderived SOA, indicating that major organic PM OP contributors could be less volatile than previously thought, and may more readily remain in the particle phase under atmospheric aging. Nevertheless, future work should focus on improving separation methods, allowing for more precise measurements of OP from SOA oligomeric constituents.

$A$ reduction in OP was observed when mixing NSOA/PSOA with $\mathrm{Cu}$ (II), resulting in a non-additive effect. However, no such reduction was observed in $\alpha$-pinene SOA or limonene SOA. Using ${ }^{1} \mathrm{H}$ NMR spectroscopy, we demonstrate that the reduction in OP is likely caused by binding between $\mathrm{Cu}$ (II) and redox active organic compounds. Both the peak broadening in 1-D NMR spectra and shorter relaxation times are observed for compounds that exhibited OP reduction (1,2-NQN, 2,3-DHN) upon $\mathrm{Cu}$ (II) mixing. Additionally, with a greater amount of $\mathrm{Cu}$ (II) mixed in, an enhanced OP reduction and a decrease in relaxation times appeared. While it is still challenging to determine which NSOA components are binding with $\mathrm{Cu}$ (II), the overall relaxation time also decreased when NSOA was mixed with $\mathrm{Cu}$ (II), indicating binding between $\mathrm{Cu}$ (II) and various NSOA components. Based on our work, previously recognized redox-active organic and inorganic components in ambient particles (Charrier and Anastasio, 2012; McWhinney et al., 2011; Monks et al., 1992; Turski and Thiele, 2009) may bind with each other once mixed during atmospheric aging processes (externally) or within the physiological environment of the human body (internally). Similarly, Hems et al. (2017) found that suppression of $\mathrm{OH}$ generation (photo-Fenton reaction) occurred, and attributed the decrease to the formation of metal-SOA complex. Although current studies demonstrate such metal-SOA binding leads to a lower OP, other studies (Gonzalez et al., 2017; Yu et al., 2018) have found an increased level of $\mathrm{OH}$ radicals through the formation of Fe (II)-HULIS complex. These synergistic/antagonistic metal-organic interactions are relevant to multiple health outcomes. Figuring out the dominant interactions under atmospherically/physically relevant conditions may provide hints for alleviating the health impact of ambient particles. In the future, a more detailed understanding of SOA binding with metal components and the effects on the oxidative health outcomes will be essential. It should also be noted that the DTT assay alone may not be entirely representative of physiological ROS variations (Tuet et al., 2017a; Xiong et al., 2017). More in vitro and in vivo work should be performed to establish the relationship between chemical composition and the OP of aerosol.

Data availability. Data used in this study can be provided upon request to the corresponding author.

\section{The Supplement related to this article is available online at https://doi.org/10.5194/acp-18-3987-2018-supplement.}

Competing interests. The authors declare that they have no conflict of interest.

Acknowledgements. This work was supported by Natural Sciences and Engineering Research Council Discovery Grant, Canadian Foundation for Innovation John R Evans Leaders Fund, and the Ontario Early Researcher Award. The authors would like to thank Jon Abbatt, Greg Evans, and Manpreet Takhar for helpful discussion.

Edited by: Manabu Shiraiwa

Reviewed by: two anonymous referees

\section{References}

Altieri, K., Seitzinger, S., Carlton, A., Turpin, B., Klein, G., and Marshall, A.: Oligomers formed through in-cloud methylglyoxal reactions: Chemical composition, properties, and mechanisms investigated by ultra-high resolution FT-ICR mass spectrometry, Atmos. Environ., 42, 1476-1490, 2008.

Antiñolo, M., Willis, M. D., Zhou, S., and Abbatt, J. P. D.: Connecting the oxidation of soot to its redox cycling abilities, Nat. Commun., 6, 6812, 2015.

Atkinson, R. and Arey, J.: Atmospheric degradation of volatile organic compounds, Chem. Rev., 103, 4605-4638, 2003.

Banerjee, D. K. and Budke, C. C.: Spectrophotometric determination of traces of peroxides in organic solvents, Anal. Chem., 36, 792-796, 1964.

Beelen, R., Raaschou-Nielsen, O., Stafoggia, M., Andersen, Z. J., Weinmayr, G., Hoffmann, B., Wolf, K., Samoli, E., Fischer, P., and Nieuwenhuijsen, M.: Effects of long-term exposure to air pollution on natural-cause mortality: an analysis of 22 European cohorts within the multicentre ESCAPE project, Lancet, 383, 785-795, 2014.

Bolton, J. L., Trush, M. A., Penning, T. M., Dryhurst, G., and Monks, T. J.: Role of quinones in toxicology, Chem. Res. Toxicol., 13, 135-160, 2000. 
Brunekreef, B. and Holgate, S. T.: Air pollution and health, Lancet, 360, 1233-1242, 2002.

Chan, A. W. H., Kautzman, K. E., Chhabra, P. S., Surratt, J. D., Chan, M. N., Crounse, J. D., Kürten, A., Wennberg, P. O., Flagan, R. C., and Seinfeld, J. H.: Secondary organic aerosol formation from photooxidation of naphthalene and alkylnaphthalenes: implications for oxidation of intermediate volatility organic compounds (IVOCs), Atmos. Chem. Phys., 9, 3049-3060, https://doi.org/10.5194/acp-9-3049-2009, 2009.

Charrier, J. G. and Anastasio, C.: On dithiothreitol (DTT) as a measure of oxidative potential for ambient particles: evidence for the importance of soluble transition metals, Atmos. Chem. Phys., 12, 9321-9333, https://doi.org/10.5194/acp-12-9321-2012, 2012.

Charrier, J. G., Richards-Henderson, N. K., Bein, K. J., McFall, A. S., Wexler, A. S., and Anastasio, C.: Oxidant production from source-oriented particulate matter - Part 1: Oxidative potential using the dithiothreitol (DTT) assay, Atmos. Chem. Phys., 15, 2327-2340, https://doi.org/10.5194/acp-15-2327-2015, 2015.

Charrier, J. G., McFall, A. S., Vu, K. K., Baroi, J., Olea, C., Hasson, A., and Anastasio, C.: A bias in the "mass-normalized" DTT response-An effect of non-linear concentration-response curves for copper and manganese, Atmos. Environ., 144, 325334, 2016.

Cho, A. K., Di Stefano, E., You, Y., Rodriguez, C. E., Schmitz, D. A., Kumagai, Y., Miguel, A. H., Eiguren-Fernandez, A., Kobayashi, T., and Avol, E.: Determination of four quinones in diesel exhaust particles, SRM 1649a, and atmospheric $\mathrm{PM}_{2.5}$ special issue of aerosol science and technology on findings from the fine particulate matter supersites program, Aerosol Sci. Tech., 38, 68-81, 2004.

Cho, A. K., Sioutas, C., Miguel, A. H., Kumagai, Y., Schmitz, D. A., Singh, M., Eiguren-Fernandez, A., and Froines, J. R.: Redox activity of airborne particulate matter at different sites in the Los Angeles Basin, Environ. Res., 99, 40-47, 2005.

Chow, J. C., Watson, J. G., Pritchett, L. C., Pierson, W. R., Frazier, C. A., and Purcell, R. G.: The DRI thermal/optical reflectance carbon analysis system: description, evaluation and applications in US air quality studies, Atmos. Environ. A-Gen., 27, 11851201, 1993.

Cleland, W. W.: Dithiothreitol, a new protective reagent for $\mathrm{SH}$ groups, Biochem., 3, 480-482, 1964.

Cohen, A. J., Brauer, M., Burnett, R., Anderson, H. R., Frostad, J., Estep, K., Balakrishnan, K., Brunekreef, B., Dandona, L., and Dandona, R.: Estimates and 25-year trends of the global burden of disease attributable to ambient air pollution: an analysis of data from the Global Burden of Diseases Study 2015, Lancet, 389, 1907-1918, 2017.

Curbo, S., Reiser, K., Rundlöf, A. K., Karlsson, A., and Lundberg, M.: Is trichloroacetic acid an insufficient sample quencher of redox reactions?, Antioxid. Redox Sign., 18, 795-799, 2013.

de Kok, T. M., Driece, H. A., Hogervorst, J. G., and Briedé, J. J.: Toxicological assessment of ambient and traffic-related particulate matter: a review of recent studies, Mutat. Res.-Rev. Mutat., 613, 103-122, 2006.

Delfino, R. J., Staimer, N., Tjoa, T., Gillen, D. L., Schauer, J. J., and Shafer, M. M.: Airway inflammation and oxidative potential of air pollutant particles in a pediatric asthma panel, J. Expo. Sci. Env. Epid., 23, 466-473, 2013.
Di Lorenzo, R. A. and Young, C. J.: Size separation method for absorption characterization in brown carbon: Application to an aged biomass burning sample, Geophys. Res. Lett., 43, 458-465, 2016.

Di Lorenzo, R. A., Washenfelder, R. A., Attwood, A. R., Guo, H., Xu, L., Ng, N. L., Weber, R. J., Baumann, K., Edgerton, E., and Young, C. J.: Molecular-size-separated brown carbon absorption for biomass-burning aerosol at multiple field sites, Environ. Sci. Technol., 51, 3128-3137, 2017.

Docherty, K. S., Wu, W., Lim, Y. B., and Ziemann, P. J.: Contributions of organic peroxides to secondary aerosol formed from reactions of monoterpenes with $\mathrm{O}_{3}$, Environ. Sci. Technol., 39, 4049-4059, 2005.

Donaldson, K., Stone, V., Seaton, A., and MacNee, W.: Ambient particle inhalation and the cardiovascular system: potential mechanisms, Environ. Health Persp., 109, 523-527, 2001.

Dooley, D. M., McIntire, W. S., McGuirl, M. A., Cote, C. E., and Bates, J. L.: Characterization of the active site of Arthrobacter P1 methylamine oxidase: evidence for copperquinone interactions, J. Am. Chem. Soc., 112, 2782-2789, https://doi.org/10.1021/ja00163a047, 1990.

Fang, T., Guo, H., Verma, V., Peltier, R. E., and Weber, R. J.: $\mathrm{PM}_{2.5}$ water-soluble elements in the southeastern United States: automated analytical method development, spatiotemporal distributions, source apportionment, and implications for heath studies, Atmos. Chem. Phys., 15, 11667-11682, https://doi.org/10.5194/acp-15-11667-2015, 2015.

Fang, T., Verma, V., Bates, J. T., Abrams, J., Klein, M., Strickland, M. J., Sarnat, S. E., Chang, H. H., Mulholland, J. A., Tolbert, P. E., Russell, A. G., and Weber, R. J.: Oxidative potential of ambient water-soluble $\mathrm{PM}_{2.5}$ in the southeastern United States: contrasts in sources and health associations between ascorbic acid (AA) and dithiothreitol (DTT) assays, Atmos. Chem. Phys., 16, 3865-3879, https://doi.org/10.5194/acp-16-3865-2016, 2016.

Finlayson-Pitts, B. J. and Pitts Jr, J. N.: Chemistry of the upper and lower atmosphere: theory, experiments, and applications, Academic press, San Diego, 2000.

Gao, S., Ng, N. L., Keywood, M., Varutbangkul, V., Bahreini, R., Nenes, A., He, J., Yoo, K. Y., Beauchamp, J. L., and Hodyss, R. P.: Particle phase acidity and oligomer formation in secondary organic aerosol, Environ. Sci. Technol., 38, 6582-6589, 2004.

George, I. and Abbatt, J.: Heterogeneous oxidation of atmospheric aerosol particles by gas-phase radicals, Nat. Chem., 2, 713-722, 2010.

Godri, K. J., Harrison, R. M., Evans, T., Baker, T., Dunster, C., Mudway, I. S., and Kelly, F. J.: Increased oxidative burden associated with traffic component of ambient particulate matter at roadside and urban background schools sites in London, PloS one, 6, e21961, https://doi.org/10.1371/journal.pone.0021961, 2011.

Gojova, A., Guo, B., Kota, R. S., Rutledge, J. C., Kennedy, I. M., and Barakat, A. I.: Induction of inflammation in vascular endothelial cells by metal oxide nanoparticles: effect of particle composition, Environ. Health Persp., 115, 403-409, 2007.

Gonzalez, D. H., Cala, C. K., Peng, Q., and Paulson, S. E.: HULIS enhancement of hydroxyl radical formation from $\mathrm{Fe}$ (II): Kinetics of fulvic acid-Fe (II) complexes in the presence of lung antioxidants, Environ. Sci. Technol., 51, 7676-7685, https://doi.org/10.1021/acs.est.7b01299, 2017. 
Groessl, M., Graf, S., and Knochenmuss, R.: High resolution ion mobility-mass spectrometry for separation and identification of isomeric lipids, Analyst, 140, 6904-6911, 2015.

Hallquist, M., Wenger, J. C., Baltensperger, U., Rudich, Y., Simpson, D., Claeys, M., Dommen, J., Donahue, N. M., George, C., Goldstein, A. H., Hamilton, J. F., Herrmann, H., Hoffmann, T., Iinuma, Y., Jang, M., Jenkin, M. E., Jimenez, J. L., Kiendler-Scharr, A., Maenhaut, W., McFiggans, G., Mentel, Th. F., Monod, A., Prévôt, A. S. H., Seinfeld, J. H., Surratt, J. D., Szmigielski, R., and Wildt, J.: The formation, properties and impact of secondary organic aerosol: current and emerging issues, Atmos. Chem. Phys., 9, 5155-5236, https://doi.org/10.5194/acp9-5155-2009, 2009.

Hansen, R. E., Roth, D., and Winther, J. R.: Quantifying the global cellular thiol-disulfide status, P. Natl. Acad. Sci. USA, 106, 422427, 2009.

Hems, R. F., Hsieh, J. S., Slodki, M. A., Zhou, S., and Abbatt, J. P. D.: Suppression of $\mathrm{OH}$ generation from the PhotoFenton reaction in the presence of $\alpha$-Pinene secondary organic aerosol material, Environ. Sci. Tech. Let., 4, 439-443, https://doi.org/10.1021/acs.estlett.7b00381, 2017.

Inoue, Y. and Gokel, W. G.: Cation Binding by Macrocycles, Complexation of cationic species by crown ethers, Marcel Dekker, New York, 1990

Jiang, H., Jang, M., and Yu, Z.: Dithiothreitol activity by particulate oxidizers of SOA produced from photooxidation of hydrocarbons under varied $\mathrm{NO}_{x}$ levels, Atmos. Chem. Phys., 17, 99659977, https://doi.org/10.5194/acp-17-9965-2017, 2017.

Jimenez, J. L., Canagaratna, M. R., Donahue, N. M., Prevot, A. S. H., Zhang, Q., Kroll, J. H., DeCarlo, P. F., Allan, J. D., Coe, H., and $\mathrm{Ng}$, N. L.: Evolution of organic aerosols in the atmosphere, Science, 326, 1525-1529, 2009.

Jokinen, T., Sipilä, M., Richters, S., Kerminen, V. M., Paasonen, P., Stratmann, F., Worsnop, D., Kulmala, M., Ehn, M., and Herrmann, H.: Rapid autoxidation forms highly oxidized $\mathrm{RO}_{2}$ radicals in the atmosphere, Angew. Chem. Int. Edit., 53, 1459614600, 2014.

Kalberer, M., Paulsen, D., Sax, M., Steinbacher, M., Dommen, J., Prevot, A., Fisseha, R., Weingartner, E., Frankevich, V., and Zenobi, R.: Identification of polymers as major components of atmospheric organic aerosols, Science, 303, 1659-1662, 2004.

Kautzman, K. E., Surratt, J. D., Chan, M. N., Chan, A. W. H., Hersey, S. P., Chhabra, P. S., Dalleska, N. F., Wennberg, P. O., Flagan, R. C., and Seinfeld, J. H.: Chemical composition of gasand aerosol-phase products from the photooxidation of naphthalene, J. Phys. Chem. A, 114, 913-934, 2010.

Keywood, M. D., Kroll, J. H., Varutbangkul, V., Bahreini, R., Flagan, R. C., and Seinfeld, J. H.: Secondary organic aerosol formation from cyclohexene ozonolysis: Effect of $\mathrm{OH}$ scavenger and the role of radical chemistry, Environ. Sci. Technol., 38, 33433350, 2004.

Klinman, J. P.: Mechanisms whereby mononuclear copper proteins functionalize organic substrates, Chem. Rev., 96, 2541-2562, 1996.

Kostenidou, E., Pathak, R. K., and Pandis, S. N.: An algorithm for the calculation of secondary organic aerosol density combining AMS and SMPS data, Aerosol Sci. Tech., 41, 1002-1010, 2007.
Kowalewski, J. and Maler, L.: Nuclear spin relaxation in liquids: theory, experiments, and applications, CRC press, Boca Raton, 2006.

Kramer, A. J., Rattanavaraha, W., Zhang, Z., Gold, A., Surratt, J. D., and Lin, Y.-H.: Assessing the oxidative potential of isoprenederived epoxides and secondary organic aerosol, Atmos. Environ., 130, 211-218, 2016.

Krapf, M., El Haddad, I., Bruns, E. A., Molteni, U., Daellenbach, Kaspar R., Prévôt, A. S. H., Baltensperger, U., and Dommen, J.: Labile peroxides in secondary organic aerosol, Chem, 1, 603616, 2016.

Krapf, M., Künzi, L., Allenbach, S., Bruns, E. A., Gavarini, I., ElHaddad, I., Slowik, J. G., Prévôt, A. S. H., Drinovec, L., and Močnik, G.: Wood combustion particles induce adverse effects to normal and diseased airway epithelia, Environ. Sci. Proc. Impacts, 19, 538-548, 2017.

Krechmer, J. E., Groessl, M., Zhang, X., Junninen, H., Massoli, P., Lambe, A. T., Kimmel, J. R., Cubison, M. J., Graf, S., Lin, Y.-H., Budisulistiorini, S. H., Zhang, H., Surratt, J. D., Knochenmuss, R., Jayne, J. T., Worsnop, D. R., Jimenez, J.-L., and Canagaratna, M. R.: Ion mobility spectrometry-mass spectrometry (IMS-MS) for on- and offline analysis of atmospheric gas and aerosol species, Atmos. Meas. Tech., 9, 3245-3262, https://doi.org/10.5194/amt-9-3245-2016, 2016.

Kroll, J. H., Smith, J. D., Che, D. L., Kessler, S. H., Worsnop, D. R., and Wilson, K. R.: Measurement of fragmentation and functionalization pathways in the heterogeneous oxidation of oxidized organic aerosol, Phys. Chem. Chem. Phys., 11, 8005-8014, 2009.

Kroll, J. H., Donahue, N. M., Jimenez, J. L., Kessler, S. H., Canagaratna, M. R., Wilson, K. R., Altieri, K. E., Mazzoleni, L. R., Wozniak, A. S., and Bluhm, H.: Carbon oxidation state as a metric for describing the chemistry of atmospheric organic aerosol, Nat. Chem., 3, 133-139, 2011.

Kumagai, Y., Koide, S., Taguchi, K., Endo, A., Nakai, Y., Yoshikawa, T., and Shimojo, N.: Oxidation of proximal protein sulfhydryls by phenanthraquinone, a component of diesel exhaust particles, Chem. Res. Toxicol., 15, 483-489, 2002.

Lee, J. Y. and Lane, D. A.: Unique products from the reaction of naphthalene with the hydroxyl radical, Atmos. Environ., 43, 4886-4893, 2009.

Lelieveld, J., Evans, J. S., Fnais, M., Giannadaki, D., and Pozzer, A.: The contribution of outdoor air pollution sources to premature mortality on a global scale, Nature, 525, 367-371, 2015.

Li, N., Hao, M., Phalen, R. F., Hinds, W. C., and Nel, A. E.: Particulate air pollutants and asthma: a paradigm for the role of oxidative stress in PM-induced adverse health effects, Clin. Immunol., 109, 250-265, 2003a.

Li, N., Sioutas, C., Cho, A., Schmitz, D., Misra, C., Sempf, J., Wang, M., Oberley, T., Froines, J., and Nel, A.: Ultrafine particulate pollutants induce oxidative stress and mitochondrial damage, Environ. Health Persp., 111, 455-460, 2003 b.

Lim, C. Y., Browne, E. C., Sugrue, R. A., and Kroll, J. H.: Rapid heterogeneous oxidation of organic coatings on submicron aerosols, Geophys. Res. Lett., 44, 2949-2957, 2017.

Lin, Y., Arashiro, M., Martin, E., Chen, Y., Zhang, Z., Sexton, K. G., Gold, A., Jaspers, I., Fry, R. C., and Surratt, J. D.: Isoprenederived secondary organic aerosol induces the expression of oxidative stress response genes in human lung cells, Environ. Sci Tech. Let., 3, 250-254, 2016. 
Manke, A., Wang, L., and Rojanasakul, Y.: Mechanisms of nanoparticle-induced oxidative stress and toxicity, Biomed. Res. Int., 2013, 1-15, 2013.

Mentel, T. F., Springer, M., Ehn, M., Kleist, E., Pullinen, I., Kurtén, T., Rissanen, M., Wahner, A., and Wildt, J.: Formation of highly oxidized multifunctional compounds: autoxidation of peroxy radicals formed in the ozonolysis of alkenes - deduced from structure-product relationships, Atmos. Chem. Phys., 15, 67456765, https://doi.org/10.5194/acp-15-6745-2015, 2015.

McWhinney, R. D., Gao, S. S., Zhou, S., and Abbatt, J. P. D.: Evaluation of the effects of ozone oxidation on redox-cycling activity of two-stroke engine exhaust particles, Environ. Sci. Technol., 45, 2131-2136, 2011.

McWhinney, R. D., Zhou, S., and Abbatt, J. P. D.: Naphthalene SOA: redox activity and naphthoquinone gasparticle partitioning, Atmos. Chem. Phys., 13, 9731-9744, https://doi.org/10.5194/acp-13-9731-2013, 2013.

Monks, T. J., Hanzlik, R. P., Cohen, G. M., Ross, D., and Graham, D. G.: Quinone chemistry and toxicity, Toxicol. Appl. Pharm., 112, 2-16, 1992.

Nel, A.: Air pollution-related illness: effects of particles, Science, 308, 804-806, 2005.

Nel, A. E., Diaz-Sanchez, D., Ng, D., Hiura, T., and Saxon, A.: Enhancement of allergic inflammation by the interaction between diesel exhaust particles and the immune system, J. Allergy. Clin. Immun., 102, 539-554, 1998.

Oberdörster, G., Oberdörster, E., and Oberdörster, J.: Nanotoxicology: an emerging discipline evolving from studies of ultrafine particles, Environ. Health Persp., 113, 823-839, 2005.

Peana, M., Medici, S., Nurchi, V. M., Lachowicz, J. I., Crisponi, G., Crespo-Alonso, M., Santos, M. A., and Zoroddu, M. A.: An NMR study on the 6,6'(2-(diethylamino)ethylazanediyl)bis(methylene)bis(5-

hydroxy-2-hydroxymethyl-4H-pyran-4-one) interaction with AlIII and ZnII ions, J. Inorg. Biochem., 148, 69-77, https://doi.org/10.1016/j.jinorgbio.2015.01.016, 2015.

Pope, C. A., Burnett, R. T., Thun, M. J., Calle, E. E., Krewski, D., Ito, K., and Thurston, G. D.: Lung cancer, cardiopulmonary mortality, and long-term exposure to fine particulate air pollution, Jama, 287, 1132-1141, 2002.

Pope, C. A., Ezzati, M., and Dockery, D. W.: Fine-particulate air pollution and life expectancy in the United States, N. Engl. J. Med., 2009, 376-386, 2009.

Pöschl, U. and Shiraiwa, M.: Multiphase chemistry at the atmosphere-biosphere interface influencing climate and public health in the anthropocene, Chem. Rev., 115, 4440-4475, 2015.

Rehmann, J. P. and Barton, J. K.: Proton NMR studies of tris (phenanthroline) metal complexes bound to oligonucleotides: characterization of binding modes, Biochem., 29, 1701-1709, 1990.

Rhee, S. G.: $\mathrm{H}_{2} \mathrm{O}_{2}$, a necessary evil for cell signaling, Science, 312, 1882-1883, 2006.

Risom, L., Møller, P., and Loft, S.: Oxidative stress-induced DNA damage by particulate air pollution, Mutat. Res-Fund. Mol. M., 592, 119-137, 2005.

Rudich, Y., Donahue, N. M., and Mentel, T. F.: Aging of organic aerosol: Bridging the gap between laboratory and field studies, Annu. Rev. Phys. Chem., 58, 321-352, 2007.
Schmidt, M. H., Miskelly, G. M., and Lewis, N. S.: Effects of redox potential, steric configuration, solvent, and alkali metal cations on the binding of carbon dioxide to cobalt (I) and nickel (I) macrocycles, J. Am. Chem. Soc., 112, 3420-3426, 1990.

Shen, H., Barakat, A. I., and Anastasio, C.: Generation of hydrogen peroxide from San Joaquin Valley particles in a cell-free solution, Atmos. Chem. Phys., 11, 753-765, https://doi.org/10.5194/acp11-753-2011, 2011.

Shilling, J. E., Chen, Q., King, S. M., Rosenoern, T., Kroll, J. H., Worsnop, D. R., DeCarlo, P. F., Aiken, A. C., Sueper, D., Jimenez, J. L., and Martin, S. T.: Loading-dependent elemental composition of a-pinene SOA particles, Atmos. Chem. Phys., 9, 771-782, https://doi.org/10.5194/acp-9-771-2009, 2009.

Shiraiwa, M., Selzle, K., and Pöschl, U.: Hazardous components and health effects of atmospheric aerosol particles: reactive oxygen species, soot, polycyclic aromatic compounds and allergenic proteins, Free. Radical. Res., 46, 927-939, 2012.

Simpson, A. J., McNally, D. J., and Simpson, M. J.: NMR spectroscopy in environmental research: from molecular interactions to global processes, Prog. Nucl. Mag. Res. Sp., 58, 97-175, 2011.

Simpson, M. J. and Simpson, A. J.: NMR Spectroscopy: A Versatile Tool for Environmental Research, John Wiley \& Sons, New York, 2014.

Smith, M. E. and van Eck, E. R.: Recent advances in experimental solid state NMR methodology for half-integer spin quadrupolar nuclei, Prog. Nucl. Mag. Res. Sp., 34, 159-201, 1999.

Surratt, J. D., Chan, A. W. H., Eddingsaas, N. C., Chan, M., Loza, C. L., Kwan, A. J., Hersey, S. P., Flagan, R. C., Wennberg, P. O., and Seinfeld, J. H.: Reactive intermediates revealed in secondary organic aerosol formation from isoprene, P. Natl. Acad. Sci. USA, 107, 6640-6645, https://doi.org/10.1073/pnas.0911114107, 2010.

Syme, C. D. and Viles, J. H.: Solution $1 \mathrm{H}$ NMR investigation of $\mathrm{Zn}{ }^{2+}$ and $\mathrm{Cd}^{2+}$ binding to amyloid-beta peptide $(\mathrm{A} \beta)$ of Alzheimer's disease, BBA-Proteins and Proteom., 1764, 246256, 2006.

Thurston, G. D., Burnett, R. T., Turner, M. C., Shi, Y., Krewski, D., Lall, R., Ito, K., Jerrett, M., Gapstur, S. M., and Diver, W. R.: Ischemic heart disease mortality and long-term exposure to source-related components of US fine particle air pollution, Environ. Health Persp., 124, 785-794, 2016.

Tolman, C. A.: Steric effects of phosphorus ligands in organometallic chemistry and homogeneous catalysis, Chem. Rev., 77, 313348, 1977.

Tolocka, M. P., Jang, M., Ginter, J. M., Cox, F. J., Kamens, R. M., and Johnston, M. V.: Formation of oligomers in secondary organic aerosol, Environ. Sci. Technol., 38, 1428-1434, 2004.

Tong, H., Arangio, A. M., Lakey, P. S. J., Berkemeier, T., Liu, F., Kampf, C. J., Brune, W. H., Pöschl, U., and Shiraiwa, M.: Hydroxyl radicals from secondary organic aerosol decomposition in water, Atmos. Chem. Phys., 16, 1761-1771, https://doi.org/10.5194/acp-16-1761-2016, 2016.

Trump, E. R. and Donahue, N. M.: Oligomer formation within secondary organic aerosols: equilibrium and dynamic considerations, Atmos. Chem. Phys., 14, 3691-3701, https://doi.org/10.5194/acp-14-3691-2014, 2014.

Tuet, W. Y., Chen, Y., Fok, S., Champion, J. A., and Ng, N. L.: Inflammatory responses to secondary organic aerosols (SOA) generated from biogenic and anthropogenic precursors, Atmos. 
Chem. Phys., 17, 11423-11440, https://doi.org/10.5194/acp-1711423-2017, 2017a.

Tuet, W. Y., Chen, Y., Xu, L., Fok, S., Gao, D., Weber, R. J., and Ng, N. L.: Chemical oxidative potential of secondary organic aerosol (SOA) generated from the photooxidation of biogenic and anthropogenic volatile organic compounds, Atmos. Chem. Phys., 17, 839-853, https://doi.org/10.5194/acp-17-839-2017, $2017 \mathrm{~b}$.

Turski, M. L. and Thiele, D. J.: New roles for copper metabolism in cell proliferation, signaling, and disease, J. Biol. Chem., 284, 717-721, 2009.

Valavanidis, A., Fiotakis, K., Bakeas, E., and Vlahogianni, T.: Electron paramagnetic resonance study of the generation of reactive oxygen species catalysed by transition metals and quinoid redox cycling by inhalable ambient particulate matter, Redox. Rep., 10, 37-51, 2005.

Verma, V., Ning, Z., Cho, A. K., Schauer, J. J., Shafer, M. M., and Sioutas, C.: Redox activity of urban quasi-ultrafine particles from primary and secondary sources, Atmos. Environ., 43, 63606368, 2009.

Verma, V., Fang, T., Xu, L., Peltier, R. E., Russell, A. G., Ng, N. L., and Weber, R. J.: Organic aerosols associated with the generation of reactive oxygen species (ROS) by water-soluble $\mathrm{PM}_{2.5}$, Environ. Sci. Technol., 49, 4646-4656, 2015a.

Verma, V., Wang, Y., El-Afifi, R., Fang, T., Rowland, J., Russell, A. G., and Weber, R. J.: Fractionating ambient humic-like substances (HULIS) for their reactive oxygen species activityAssessing the importance of quinones and atmospheric aging, Atmos. Environ., 120, 351-359, 2015b.

Wang, L., Xu, W., Khalizov, A. F., Zheng, J., Qiu, C., and Zhang, R.: Laboratory investigation on the role of organics in atmospheric nanoparticle growth, J. Phys. Chem. A, 115, 8940-8947, 2011.
Xiong, Q., Yu, H., Wang, R., Wei, J., and Verma, V.: Rethinking the dithiothreitol (DTT) based PM oxidative potential: Measuring DTT consumption versus ROS generation, Environ. Sci. Technol., 51, 6507-6514, 2017.

Ye, J., Gordon, C. A., and Chan, A. W. H.: Enhancement in secondary organic aerosol formation in the presence of preexisting organic particle, Environ. Sci. Technol., 50, 3572-3579, 2016.

Ye, J., Salehi, S., North, M. L., Portelli, A. M., Chow, C.-W., and Chan, A. W. H.: Development of a novel simulation reactor for chronic exposure to atmospheric particulate matter, Sci. Rep., 7, 42317, 2017.

Yu, H., Wei, J., Cheng, Y., Subedi, K., and Verma, V.: Synergistic and antagonistic interactions among the particulate matter components in generating reactive oxygen species based on the dithiothreitol assay, Environ. Sci. Technol., 52, 2261-2270, 2018.

Zhang, X., McVay, R. C., Huang, D. D., Dalleska, N. F., Aumont, B., Flagan, R. C., and Seinfeld, J. H.: Formation and evolution of molecular products in $\alpha$-pinene secondary organic aerosol, $\mathrm{P}$. Natl. Acad. Sci. USA, 112, 14168-14173, 2015.

Zhang, X., Lambe, A. T., Upshur, M. A., Brooks, W. A., Gray Be, A., Thomson, R. J., Geiger, F. M., Surratt, J. D., Zhang, Z., and Gold, A.: Highly Oxygenated Multifunctional Compounds in $\alpha$ pinene Secondary Organic Aerosol, Environ. Sci. Technol., 51, 5932-5940, 2017. 